\title{
SERI Photovoltaic Subcontract Reports: 1988 Abstracts and Document Control Information
}

Photovoltaic Program Branch

June 1990

Prepared under Task No. PV040101

Solar Energy Research Institute

A Division of Midwest Research Institute

1617 Cole Boulevard

Golden, Colorado 80401-3393

Prepared for the

U.S. Department of Energy

Contract No. DE-AC02-83CH10093 


\section{NOTICE}

This report was prepared as an account of work sponsored by an agency of the United States government. Neither the United States government nor any agency thereof, nor any of their employees, makes any warranty, express or implied, or assumes any legal liability or responsibility for the accuracy, completeness, or usefulness of any information, apparatus, product, or process disclosed, or represents that its use would not infringe privately owned rights. Reference herein to any specific commercial product, process, or service by trade name, trademark, manufacturer, or otherwise does not necessarily constitute or imply its endorsement, recommendation, or favoring by the United States government or any agency thereof. The views and opinions of authors expressed herein do not necessarily state or reflect those of the United States government or any agency thereof.

Printed in the United States of America

Available from:

National Technical Information Service

U.S. Department of Commerce

5285 Port Royal Road

Springfield, VA 22161

Price: Microfiche A01

Printed Copy $\mathrm{AOS}$

Codes are used for pricing all publications. The code is determined by the number of pages in the publication. Information pertaining to the pricing codes can be found in the current issue of the following publications which are generally available in most libraries: Energy Research Abstracts (ERA); Government Reports Announcements and Index (GRA and I); Scientific and Technical Abstract Reports (STAR); and publication NTIS-PR-360 available from NTIS at the above address. 


\section{PREFACE}

This report contains the document control information and abstracts for SERI Photovoltaic (PV) Program Branch publications resulting from SERI's subcontracted PV research. The information is presented for reports published or distributed during fiscal year (FY) 1988. In the past, copies of the subcontractor reports were distributed to a broad spectrum of researchers in the field of photovoltaics at a considerable cost to the program. In an attempt to reduce costs and ensure that all researchers receive those current publications that are of specific interest to them, this report will outline these publications, organized by technology, on a regular basis. A list of additional publications and sources is included herein to provide the photovoltaic community with other sources of information. All of the documents represented here are available from the National Technical Information Service (NTIS) and can be purchased using the NTIS order form at the end of this document. Further information on a given subcontracted program may be obtained from the SERI technical monitor identified on each Document Control Page.

The SERI Photovoltaic Program is sponsored by the U.S. Department of Energy under contract No. DE-AC02-83CH10093. The Solar Energy Research Institute is operated by Midwest Research Institute for the U.S. Department of Energy. 


\section{TABLE OF CONTENTS}

Page

Amorphous Silicon Program Publications $\ldots \ldots \ldots \ldots \ldots \ldots \ldots \ldots \ldots \ldots$

Polycrystalline Thin Film Program Publications $\ldots \ldots \ldots \ldots \ldots \ldots \ldots \ldots \ldots \ldots \quad 12$

High Efficiency Program Publications $\ldots \ldots \ldots \ldots \ldots \ldots \ldots \ldots \ldots \ldots \ldots \ldots 23$

Additional Publications and Sources . . . . . . . . . . . . . . . . 27 


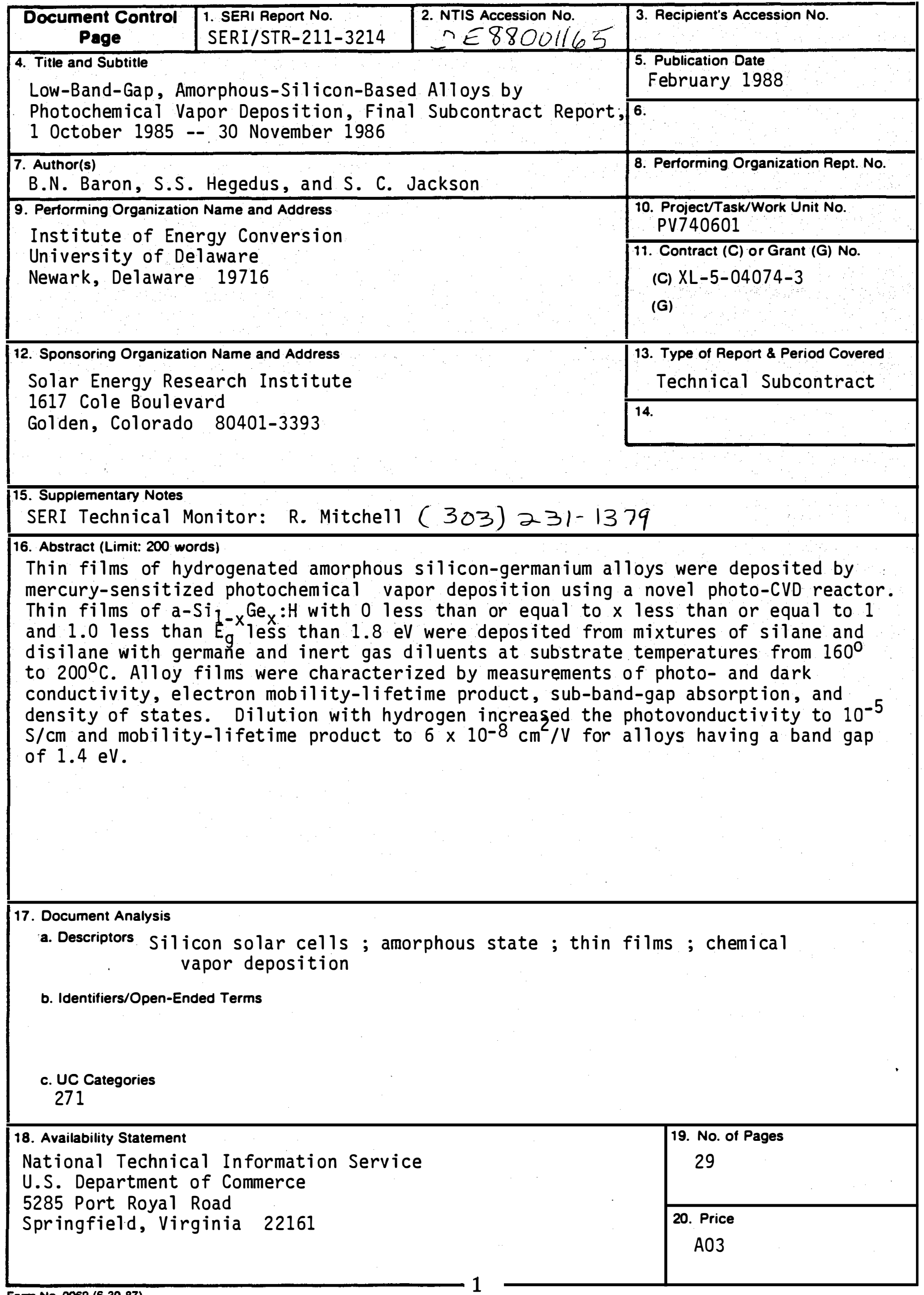




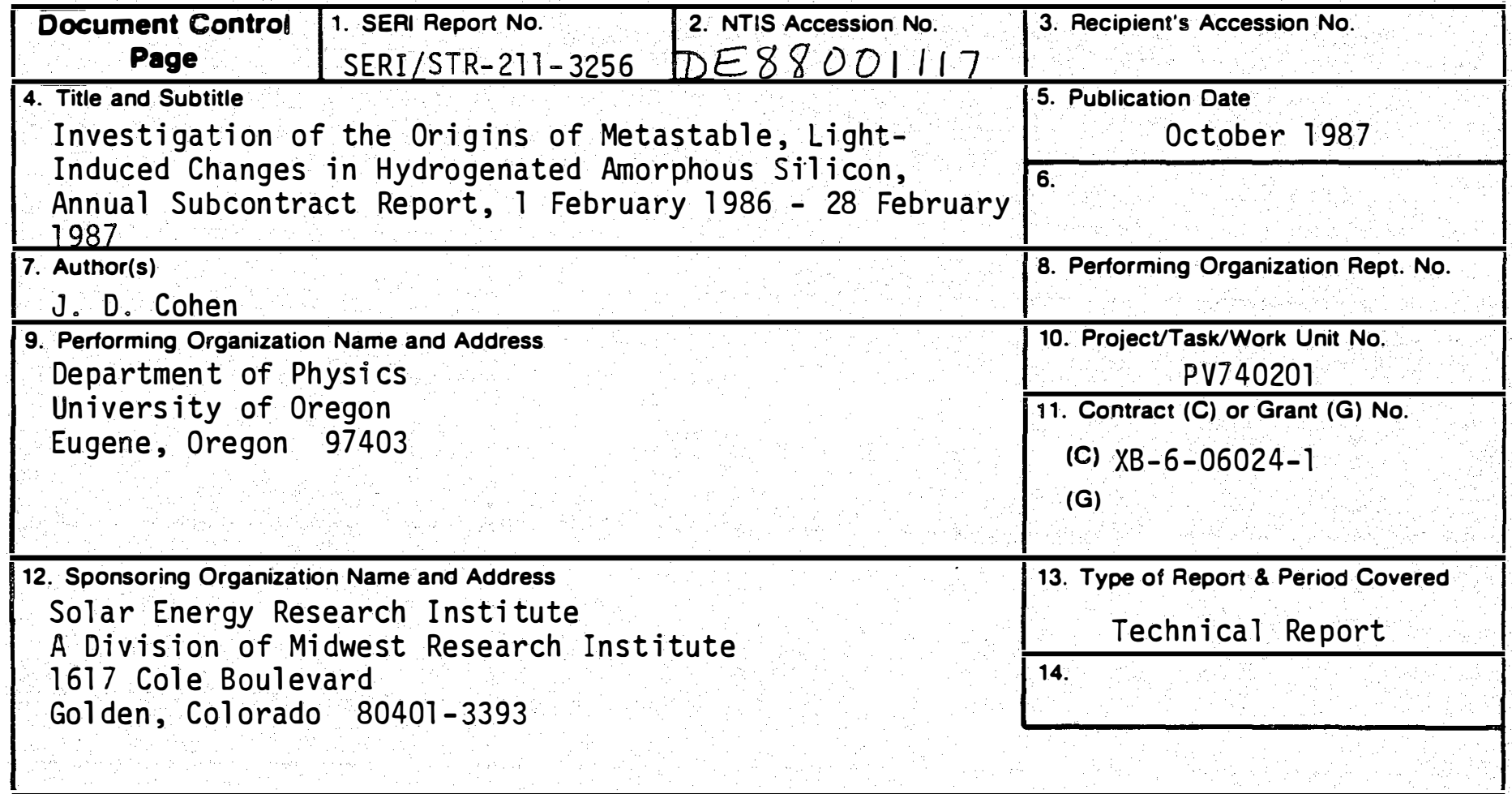

\section{Technical Monitor: Byron Stafford $(303) 231-7126$}

16. Abstract (Limit: 200 words) This report presents results of an investigation into the metastable changes in the density of deep mobility gap states in hydrogenated amorphous silicon, using a variety of junction capacitance techniques. This work extends previous studies (using drive-level capacitance profiling) to some new samples. With these measurements, researchers examined how the distribution of occupied gap states changes with light soaking and partial annealing through a series of intermediate states between states $A$ and $B$. The results on two phosphorus-free samples indicate no qualitative change from previous results, which revealed a large metastable increase in the concentration of $D^{-}$centers with light soaking, so phosphorus contamination is not crucial to this increase. Because such an increase is inconsistent with the Si-Si bond-breaking model, this result favors a model in which local configurational changes shift the gap-state energies of existing defects. Transient photocapacitance was applied to undoped films to investigate metastable changes in more detail. Results seemed to confirm the magnitude of the metastable defect creation found by drive-level analysis on the same samples.

17. Document Analysis

a. Descriptors Amorphous state; silicon solar cells; energy losses; doped materials metastable states

b. Identifiers/Open-Ended Terms

c. UC Categories

63.

18. Availability Statement
National Technical Information Service
U.S. Department of Commerce
5285 Port Royal Road
Springfield, Virginia 22161

19. No. of Pages

30

20. Price 


\begin{tabular}{|c|c|}
\hline \begin{tabular}{|l|l|} 
1. SERI Report No. & 2. NTIS Accession No. \\
SERI/STR-211-3288 & DE8800 115 |
\end{tabular} & 3. Recipient's Accession No. \\
\hline \multirow{2}{*}{$\begin{array}{l}\text { 4. Title and Subtitle } \\
\text { Diagnostics of Glow Discharges Used To Produce } \\
\text { Hydrogenated Amorphous Silicon Films, Annual Subcontract } \\
\text { Report, } 15 \text { April 1986-14 June } 1987\end{array}$} & $\begin{array}{l}\text { 5. Publication Date } \\
\text { February } 1988\end{array}$ \\
\hline & 6. \\
\hline $\begin{array}{l}\text { 7. Author(s) } \\
\text { A. Gallagher, J. Doyle, M. He, G. Lin, J. Scott }\end{array}$ & 8. Performing Organization Rept. No. \\
\hline $\begin{array}{l}\text { 9. Performing Organization Name and Address } \\
\text { National Bureau of Standards } \\
\text { Boulder, Colorado }\end{array}$ & $\begin{array}{l}\text { 10. Project/Task/Work Unit No. } \\
\text { PV740201 }\end{array}$ \\
\hline $\begin{array}{l}\text { University of Colorado } \\
\text { Boulder, Colorado }\end{array}$ & $\begin{array}{l}\text { 11. Contract (C) or Grant (G) No. } \\
\text { (C) DB-4-04078-1 } \\
\text { (G) }\end{array}$ \\
\hline \multirow{3}{*}{$\begin{array}{l}\text { 12. Sponsoring Organization Name and Adoress } \\
\text { Solar Energy Research Institute } \\
1617 \text { Cole Boulevard } \\
\text { Golden, Colorado } 80401-3393\end{array}$} & 13. Type of Report \& Period Covered \\
\hline & Technical Report \\
\hline & 14. \\
\hline \multicolumn{2}{|l|}{$\begin{array}{l}\text { 15. Supplementary Notes } \\
\text { SERI Technical Monitor: W. Luft }(303) 231-1823\end{array}$} \\
\hline
\end{tabular}

16. Abstract (Limit: 200 words)

This report presents results of research done to measure the neutral species produced in silane, silane-hydrogen, disilane, disilane-hydrogen, germane, germanehydrogen, and silane-germane discharges. Interpretation and modeling of the data in terms of discharge chemistry are also desirable. Mass-spectrometric measurements were made of the stable gases flowing through and produced in silane, disilane, and silane-germane discharges. From these observations, the discharge stoichiometry was determined and the reaction pathways that lead to film deposition clarified. The importance of one processing parameter (power/flow) is explained, and a high ratio of :germane/silane depletion in mixed-gas discharges is identified. A calculation of radical deposition in pure silane discharges shows the dominance of $\mathrm{SiH}_{3}$ deposition at low powers and suggests the reason (surface mobility) why this produce good-quality films. Measurements of postdeposition sputtering of a-Si:H films were diagnosed to yield the thickness of the H-rich, growing film surface layer, which is important in understanding and modeling the deposition reactions as well as the effect of ion bombardment on film properties and sputtering. A new, potentially high-rate deposition method was also developed and studied.

17. Document Analysis

a. Descriptors

Amorphous state; silicon solar cells; deposition; glow discharges

b. Identifiers/Open-Ended Terms

c. UC Categories

271

18. Availability Statement

National Technical Information Service

U.S. Department of Commerce

5285 Port Royal Road

Springfield, Virginia 22161
19. No. of Pages

53

20. Price

A04 


\begin{tabular}{|c|c|c|}
\hline $\begin{array}{c}\text { Document Control } \\
\text { Page }\end{array}$ & \begin{tabular}{|l|l|} 
SERI Repor No. & 2. NTIS Accession No. \\
SERI/STR-211-3231 & DE 88001108
\end{tabular} & 3. Recipient's Accession No. \\
\hline $\begin{array}{l}\text { 4. Title and Subtitle } \\
\text { Research on } \mathrm{Hig}\end{array}$ & & $\begin{array}{l}\text { 5. Publication Date } \\
\text { October } 1987\end{array}$ \\
\hline \multicolumn{2}{|c|}{$\begin{array}{l}\text { Research on High-Efficiency, Stacked, Multijunction, } \\
\text { Amorphous Silicon Alloy Thin-Film Solar Cells, Final } \\
\text { Subcontract Report, } 11 \text { October } 1983-30 \text { October } 1986\end{array}$} & 6. \\
\hline \multicolumn{2}{|l|}{ 7. Author(s) } & 8. Performing Organization Rept. No. \\
\hline \multirow{2}{*}{\multicolumn{2}{|c|}{$\begin{array}{l}\text { 9. Performing Organization Name and Address } \\
\text { Spire Corporation } \\
\text { Bedford, Massachusetts } 0.1730\end{array}$}} & $\begin{array}{c}\text { 10. Project/Task/Work Unit No. } \\
3493.10\end{array}$ \\
\hline & & $\begin{array}{l}\text { 11. Contract (C) or Grant (G) No. } \\
\text { (C) ZB-4-03055-1 } \\
\text { (G) }\end{array}$ \\
\hline \multirow{2}{*}{\multicolumn{2}{|c|}{$\begin{array}{l}\text { 12. Sponsoring Organization Name and Address } \\
\text { Solar Energy Research Institute } \\
\text { A Division of Midwest Research Institute } \\
\text { 1617 Cole Boulevard } \\
\text { Golden, Colorado } 80401-3393\end{array}$}} & $\begin{array}{l}\text { 13. Type of Report \& Period Covered } \\
\text { Technical Report }\end{array}$ \\
\hline & & 14. \\
\hline
\end{tabular}

15. Supplementary Notes
Technical Monitor: Werner Luft $(303) 231-1823$

16. Abstract (Limit: 200 words). This report covers the third year of a three-year project to develop high-efficiency, stable, multijunction amorphous silicon alloy solar cells. It describes new deposition techniques to obtain pinhole-free, a-Si:H alloy films by avoiding dust formation in the plasma; the deposition of low-absorptance, textured $\mathrm{SnO}_{2}$ layers by thermal CVD of $\mathrm{Sn}\left(\mathrm{CH}_{3}\right)$; a more stable, high-reflectance $\mathrm{Ti} / \mathrm{Ag}$ back contact; the application of the new deposition techniques to achieve efficiencies of $10.5 \%, 10.1 \%$, and $9.4 \%$ for a-Si:H $\mathrm{p}-\mathrm{i}-\mathrm{n}$ devices; the development of $\mathrm{a}-(\mathrm{Si}, \mathrm{Ge}): \mathrm{H}$ cells with efficiencies from $5.4 \%$ for $\mathrm{a}-(\mathrm{Si}, \mathrm{Ge}): \mathrm{H}$ cel $1 \mathrm{~s}$ to $7.5 \%$ for graded-bandgap cells; and the development of a-Si/a-( $\mathrm{Si}, \mathrm{Ge})$ tandem cells with $6.5 \%$ and $7.2 \%$ efficiencies.

17. Document Analysis

a. Descriptors Amorphous state; silicon solar cells ; chemical vapor deposition; graded band gaps

b. Identifiers/Open-Ended Terms

c. UC Categories

63

18. Availability Statement

National Technical Information Service

U.S. Department of Commerce

123

5285 Port Royal Road

Springfield, Virginia 22161

20. Price

A06 


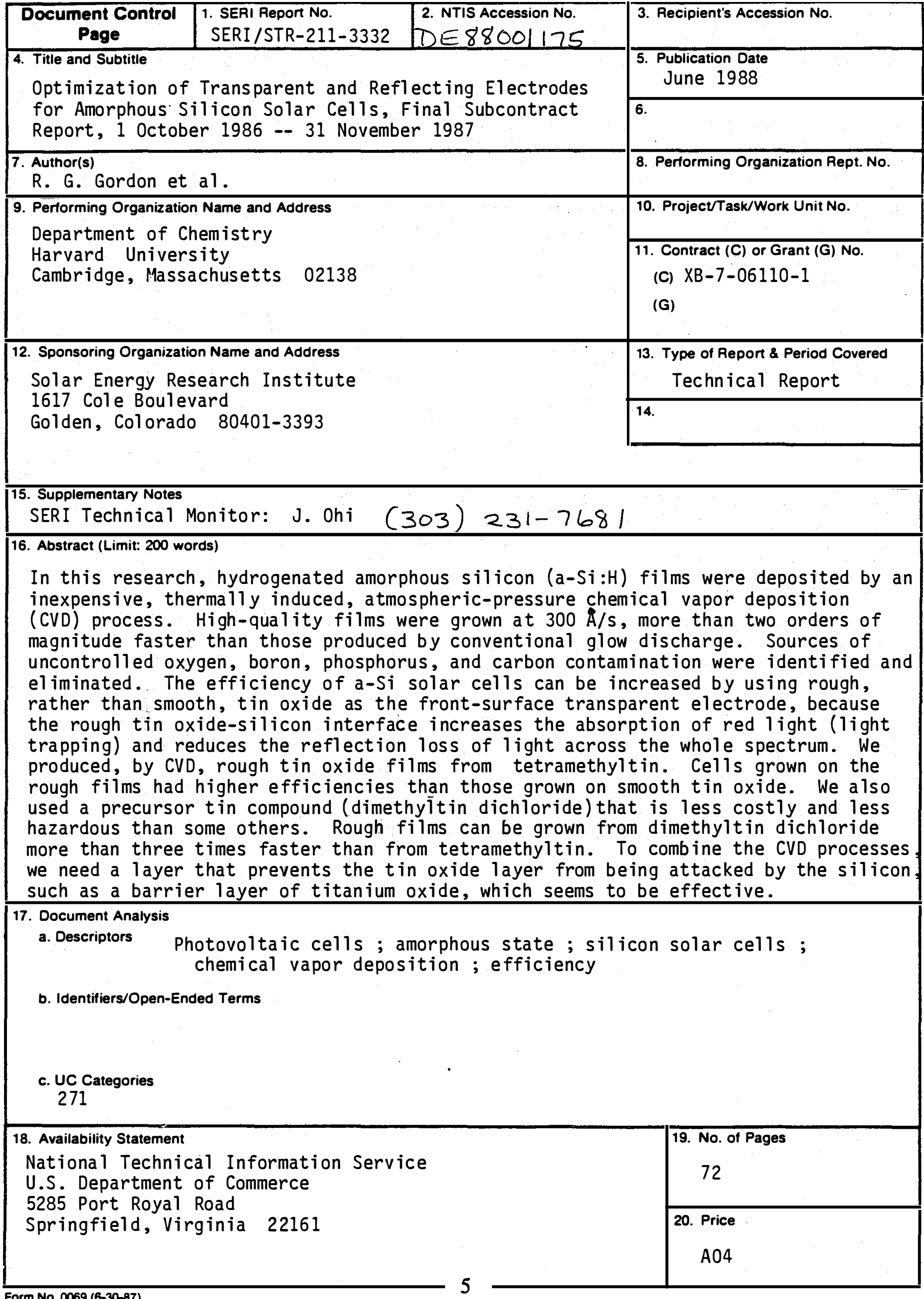




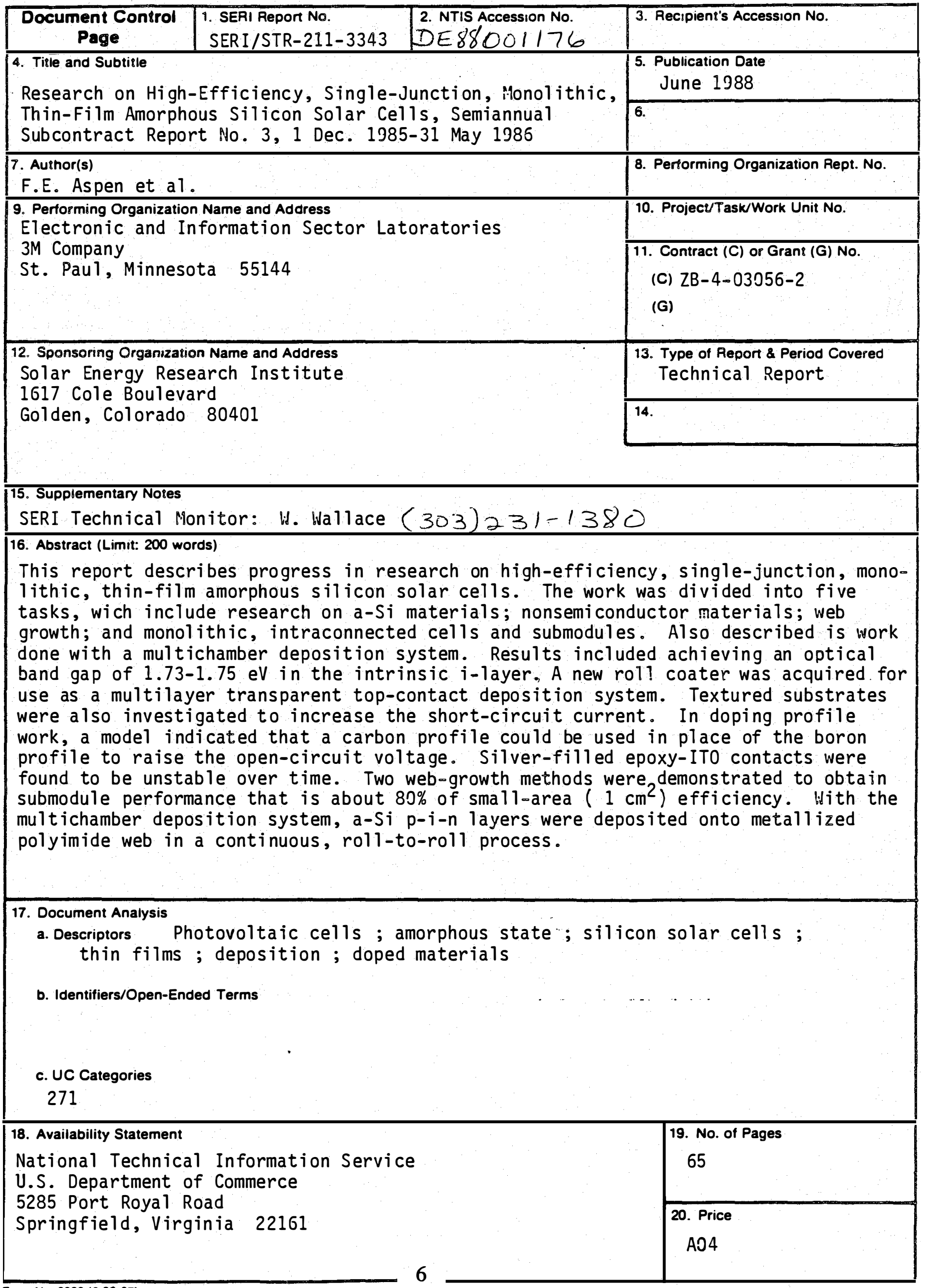




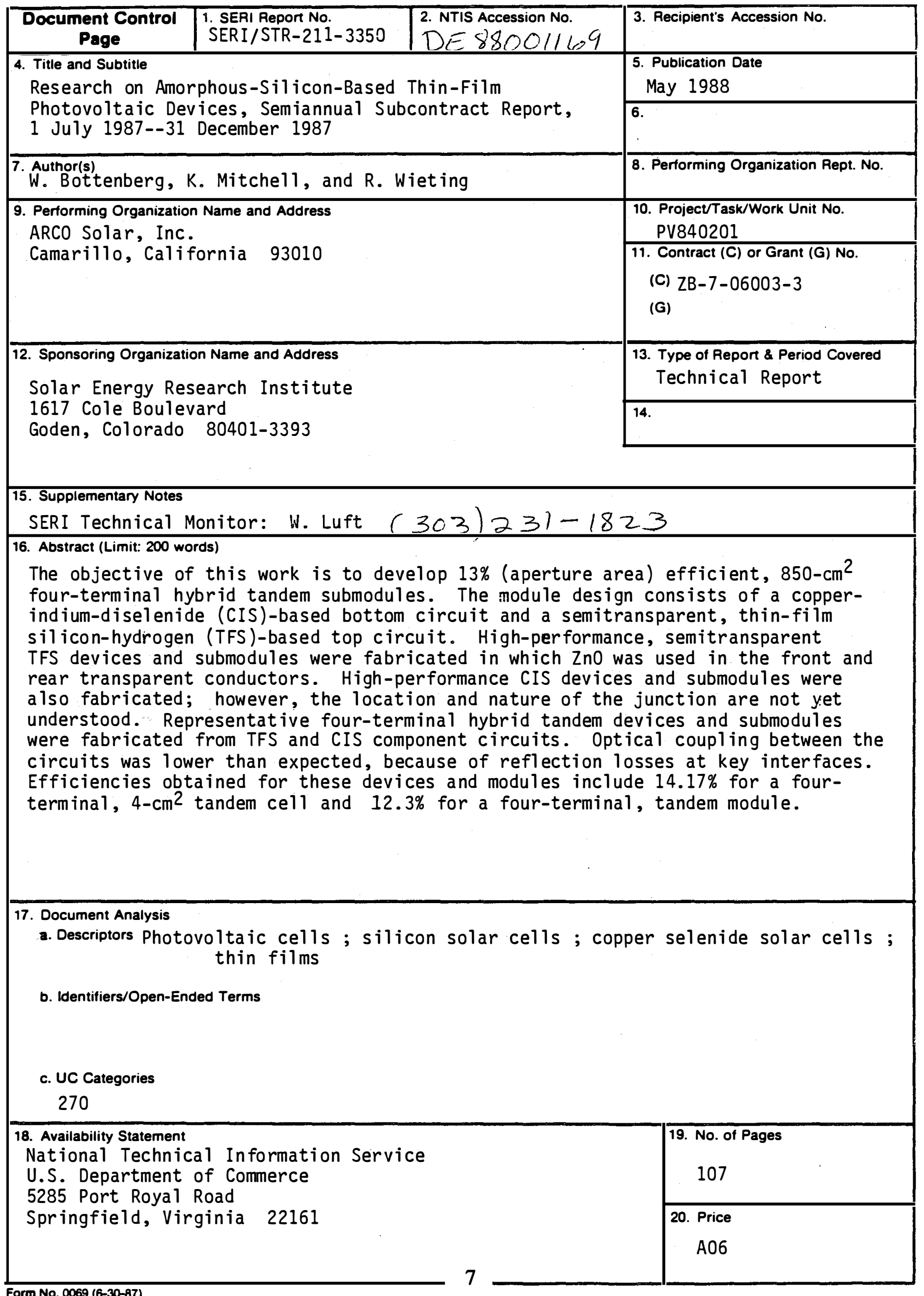




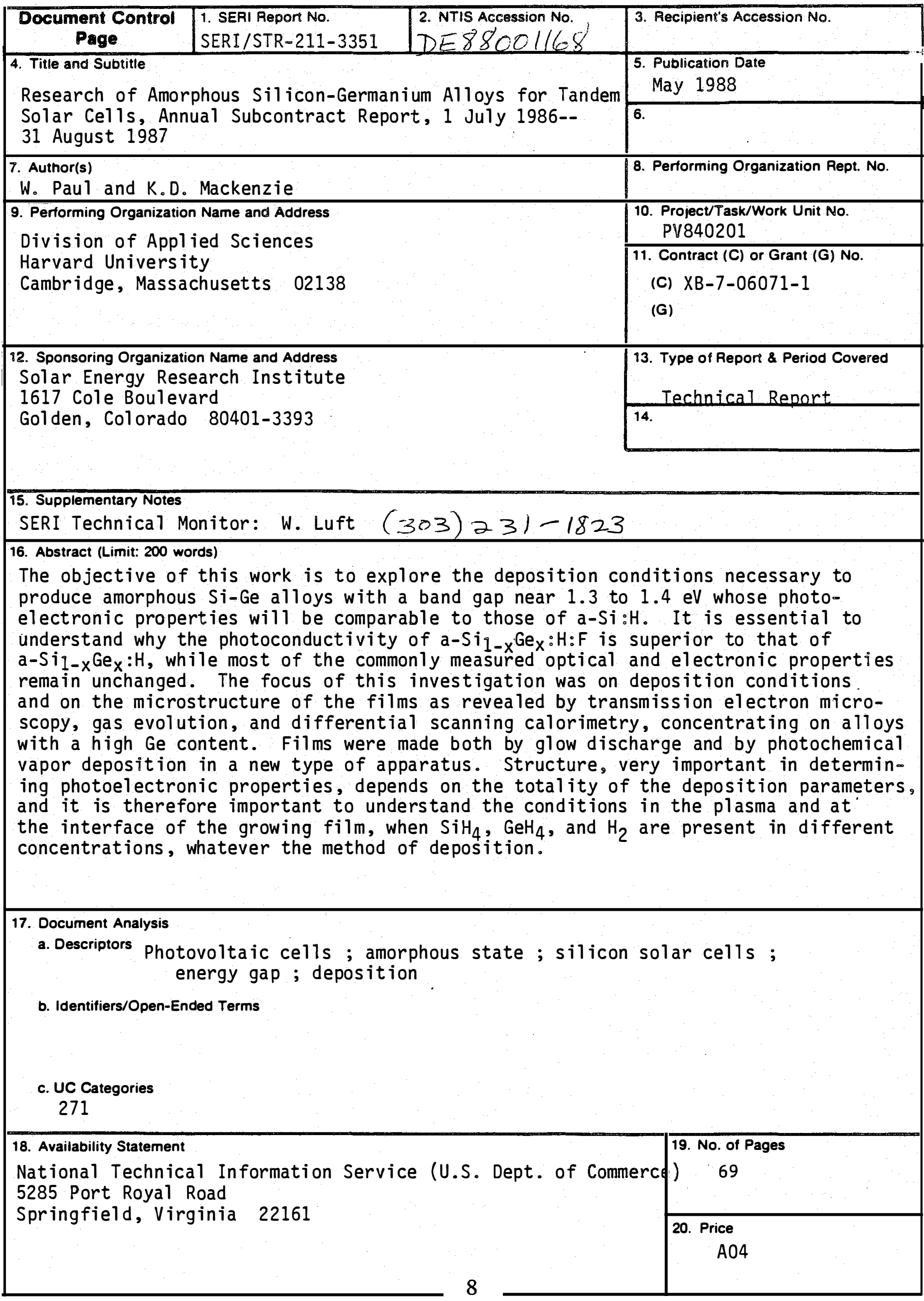




\begin{tabular}{|c|c|c|}
\hline $\begin{array}{l}\text { Document Control } \\
\text { Page }\end{array}$ & \begin{tabular}{l|l} 
1. SERI Report No. & 2. NTIS Accession No. \\
SERI/STR-211-3352 & DE 88D 0 1/67
\end{tabular} & 3. Recipient's Accession No. \\
\hline \multirow{2}{*}{\multicolumn{2}{|c|}{$\begin{array}{l}\text { 4. Title and Subtitle } \\
\text { Structure of Amorphous Silicon Alloy Films, Annual } \\
\text { Subcontract Report, I5 January 1987--14 January } 1988\end{array}$}} & $\begin{array}{l}\text { 5. Publication Date } \\
\text { May } 1988\end{array}$ \\
\hline & & 6. \\
\hline \multicolumn{2}{|c|}{$\begin{array}{l}\text { 7. Author(s) } \\
\text { R. E. Norberg and P. A. Fedders }\end{array}$} & 8. Performing Organization Rept. No. \\
\hline \multicolumn{2}{|c|}{$\begin{array}{l}\text { Department of Physics } \\
\text { Washington University } \\
\text { St. Louis, Missouri }\end{array}$} & $\begin{array}{l}\text { 11. Contract (C) or Grant (G) No. } \\
\text { (C) XB-7-06055-1 } \\
\text { (G) }\end{array}$ \\
\hline \multicolumn{2}{|c|}{ 12. Sponsoring Organization Name and Address } & 13. Type of Report \& Period Covered \\
\hline \multirow{2}{*}{\multicolumn{2}{|c|}{$\begin{array}{l}\text { Solar Energy Research Institute } \\
1617 \text { Cole Boulevard } \\
\text { Golden, Colorado } 80401-3393\end{array}$}} & Technical Report \\
\hline & & 14. \\
\hline \multicolumn{3}{|c|}{$\begin{array}{l}\text { 15. Supplementary Notes } \\
\text { SERI Technical Mon }\end{array}$} \\
\hline \multicolumn{3}{|c|}{$\begin{array}{l}\text { The principal objective of the first year of this research program was to improve } \\
\text { our understanding at the microscopic level of amorphous silicon-germanium alloy } \\
\text { films deposited under various conditions to assist researchers in producing higher } \\
\text { quality films. The method was a joint theoretical and experimental approach to the } \\
\text { correlation of muclear magnetic resonance (NMR), electron spin resonance (ESR), and } \\
\text { other characterizations, especially relating to rearrangements of hydrogen. Deuter- } \\
\text { on magnetic resonance reveals the presence of (and changes in) tightly bonded } \\
\text { hydrogen (deuterium), weakly bonded hydrogen, molecular hydrogen, and rotating silyl } \\
\text { groups. Ge-D configurations appear to be more varied than Si-D. It has been } \\
\text { shown that ESR hyperfine structure results can be interpreted very well via dangling } \\
\text { bonds, but not with floating bonds. The presence of fluorine correlates with the } \\
\text { occurrence of larger microvoid dimensions. }\end{array}$} \\
\hline \multicolumn{3}{|l|}{$\begin{array}{llll}\ldots & . & \ldots & \\
\ldots\end{array}$} \\
\hline \multicolumn{3}{|c|}{$\begin{array}{l}\text { a. Descriptors Photovoltaic cells ; amorphous state; silicon solar cells; } \\
\text { semiconductor materials; fluoride; germanium; laboratory } \\
\text { b. Identifiers/Open-Ended Terms equipment; nuclear magnetic resonance. }\end{array}$} \\
\hline \multicolumn{3}{|l|}{271} \\
\hline \multicolumn{2}{|l|}{ 18. Availability Statement } & $\overline{19 . \text { No. of Pages }}$ \\
\hline \multirow{2}{*}{\multicolumn{2}{|c|}{$\begin{array}{l}\text { National Technical Information Service } \\
\text { U.S. Department of Commerce } \\
5285 \text { Port Royal Road } \\
\text { Springfield, Virginia } 22161\end{array}$}} & 35 \\
\hline & & $\begin{array}{l}\text { 20. Price } \\
\text { A03 }\end{array}$ \\
\hline
\end{tabular}




\begin{tabular}{|c|c|c|}
\hline $\begin{array}{l}\text { Document Control } \\
\text { Page }\end{array}$ & $\begin{array}{l}\text { 1. SEAI Repor No. } \\
\text { SERI/STR-21 1-3353 }\end{array}$ & 3. Recipient's Accession No. \\
\hline \multicolumn{2}{|l|}{ 4. Title and Subtitle } & 5. Publication Date \\
\hline \multirow{2}{*}{\multicolumn{2}{|c|}{$\begin{array}{l}\text { Amorphous Silicon Photovoltaic Devices Prepared by } \\
\text { Chemical and Photochemical Vapor Deposition of Higher } \\
\text { Order Silanes, Annual Subcontract Report, } 1 \text { September } \\
1986\end{array}$}} & June 1988 \\
\hline & & 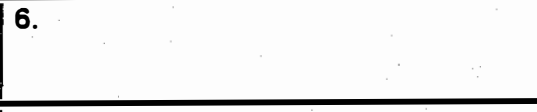 \\
\hline \multirow{2}{*}{\multicolumn{2}{|c|}{$\begin{array}{l}\text { 7. Author(s) } \\
\text { A.E. Del ahoy and H.E. Schade }\end{array}$}} & 8. Performing Organization Rept. No. \\
\hline & & \\
\hline \multicolumn{2}{|c|}{$\begin{array}{l}\text { 9. Performing Organization Name and Address } \\
\text { Chronar Corporation } \\
\text { Princeton, New Jersey } 08542\end{array}$} & 10. Projec\&/Task/Work Uni8 No. \\
\hline \multicolumn{2}{|c|}{ Princeton, New Jersey 08542} & $\begin{array}{l}\text { 81. Contract (C) or Grant (G) No. } \\
\text { (C) XB-5-04092-1 } \\
\text { (G) }\end{array}$ \\
\hline \multirow{2}{*}{\multicolumn{2}{|c|}{$\begin{array}{l}\text { 12. Sponsoring Organization Name and Address } \\
\text { Solar Energy Research Institute } \\
1617 \text { Cole Boulevard } \\
\text { Golden, Colorado } 80401\end{array}$}} & $\begin{array}{l}\text { 13. Type of Report \& Period Covered } \\
\text { Technical Report }\end{array}$ \\
\hline & & 14. \\
\hline \multicolumn{3}{|l|}{ 15. Supplementary Notes } \\
\hline
\end{tabular}

16. Abstract (Limit: 200 words)

This report describes results of research on preparing high-efficiency photovoltaic devices by photochemical vapor deposition of higher order silanes. The photostability of these devices was compared to that of devices produced by the glow-discharge technique. Hydrogenated amorphous silicon cell efficiencies of at 1east $7.5 \%$ were obtained using $p-i-n$ structures and aluminum back contacts. Using silver contacts increased the efficiency to about $8 \%$. After $\delta$ minutes of 1 ight soaking, there was no significant difference between the photostabilities of these cells and those produced by glow discharge. The efficiencies might be increased further if some remaining problems can be addressed, such as by using a different substrate preparation method or a higher pumping speed at the deposition chamber.

17. Document Analysis

a. Descriptors

Photovoltaic cells; silicon solar cells; amorphous state; efficiency

b. Identifiers/Open-Ended Terms

c. UC Categories

271

18. Availability Statement

National Technical Information Service

U.S. Department of Commerce

5285 Port Royal Road

Springfield, Virginia 22161

19. No. of Pages

30

20. Price

A03 


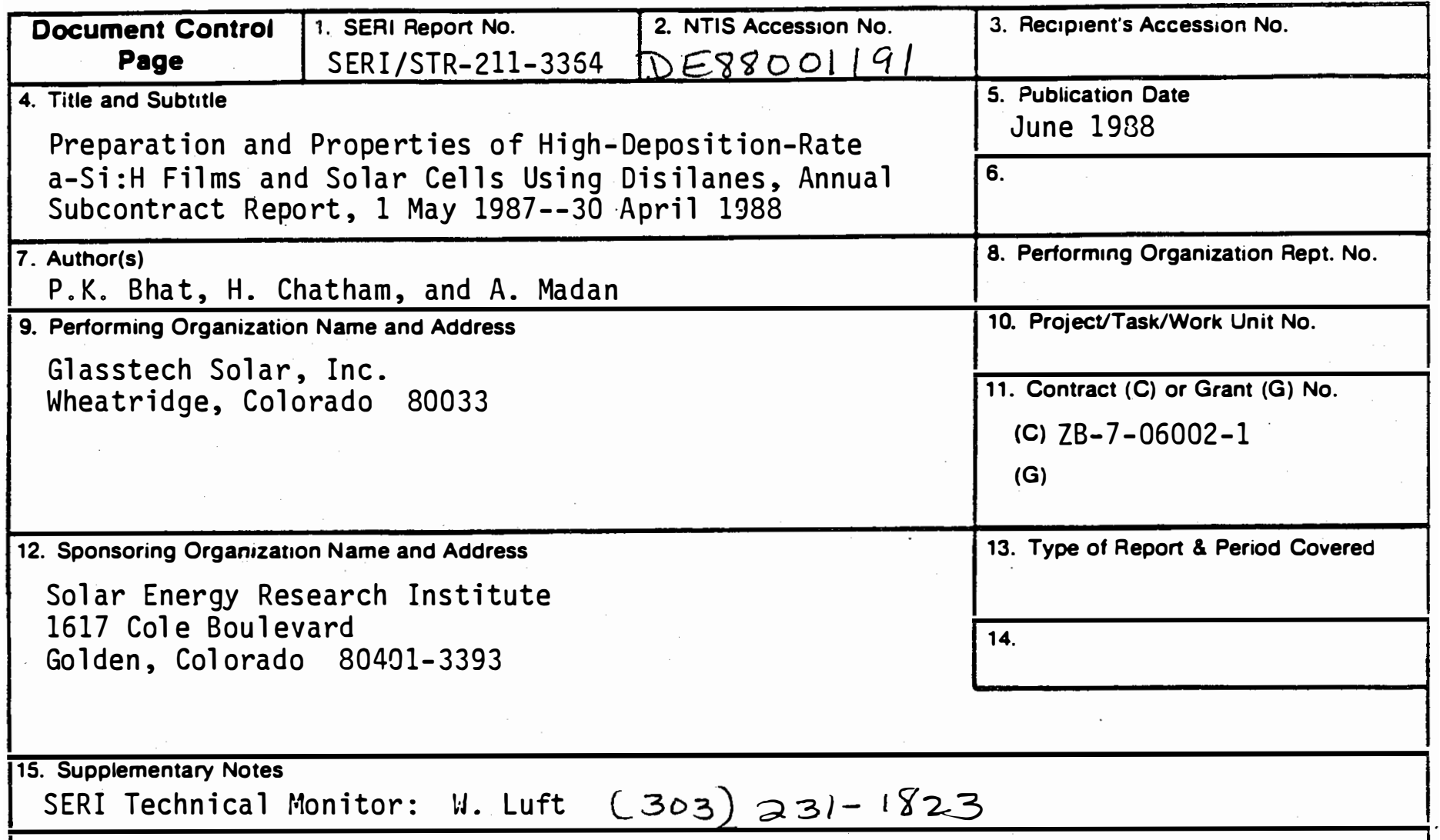

16. Abstract (Limit: 200 words)

This report contains results of the first year of research on producing $p-i-n$ amorphous silicon solar cells with the intrinsic layer deposited from higher order silanes at deposition rates of $1 \mathrm{~nm} / \mathrm{s}$ or more. The research was divided into three major areas: (1) diagnostic studies of monosilane and disilane RF discharges using optical emission spectroscopy and mass spectrometry to assist in optimizing discharge conditions and gas-phase processes; (2) parametric studies of material properties of $i$-layers prepared from disilane as a function of deposition rate and other process parameters; and (3) parametric studies of $p-i-n$ devices with the $i$-layer prepared from disilane at various deposition rates. The focus during the first year was to fabricate a $p-i-n$ solar cell with $9 \%$ A.11.5 efficiency over an area greater than $0.08 \mathrm{~cm}^{2}$ with the $i-l a y e r$ deposited at $1 \mathrm{~nm} / \mathrm{s}$ or more. ilaterial properties such as the dark and AMI.5 light conductivities, optical band gap, and conductivity activation energy showed a weak dependence on deposition rate. The performance characteristics of unoptimized $p-i-n$ solar cells with $i-l a y e r s$ prepared from disilane were independent of the deposition rate of the $i-l a y e r$. A $p-i-n$ device was prepared at a rate close to $1 \mathrm{~nm} / \mathrm{s}$ with an AM1.5 efficiency of $9 \%$.

17. Document Analysis

a. Descriptors

Photovoltaic cells; silicon solar cells; amorphous state; deposition

b. Identifiers/Open-Ended Terms

c. UC Categories

271

18. Availability Statement

National Technical Information Service

U.S. Department of Commerce

5285 Port Royal Road

Springfield, Virginia 22161

19. No. of Pages

33

20. Price 


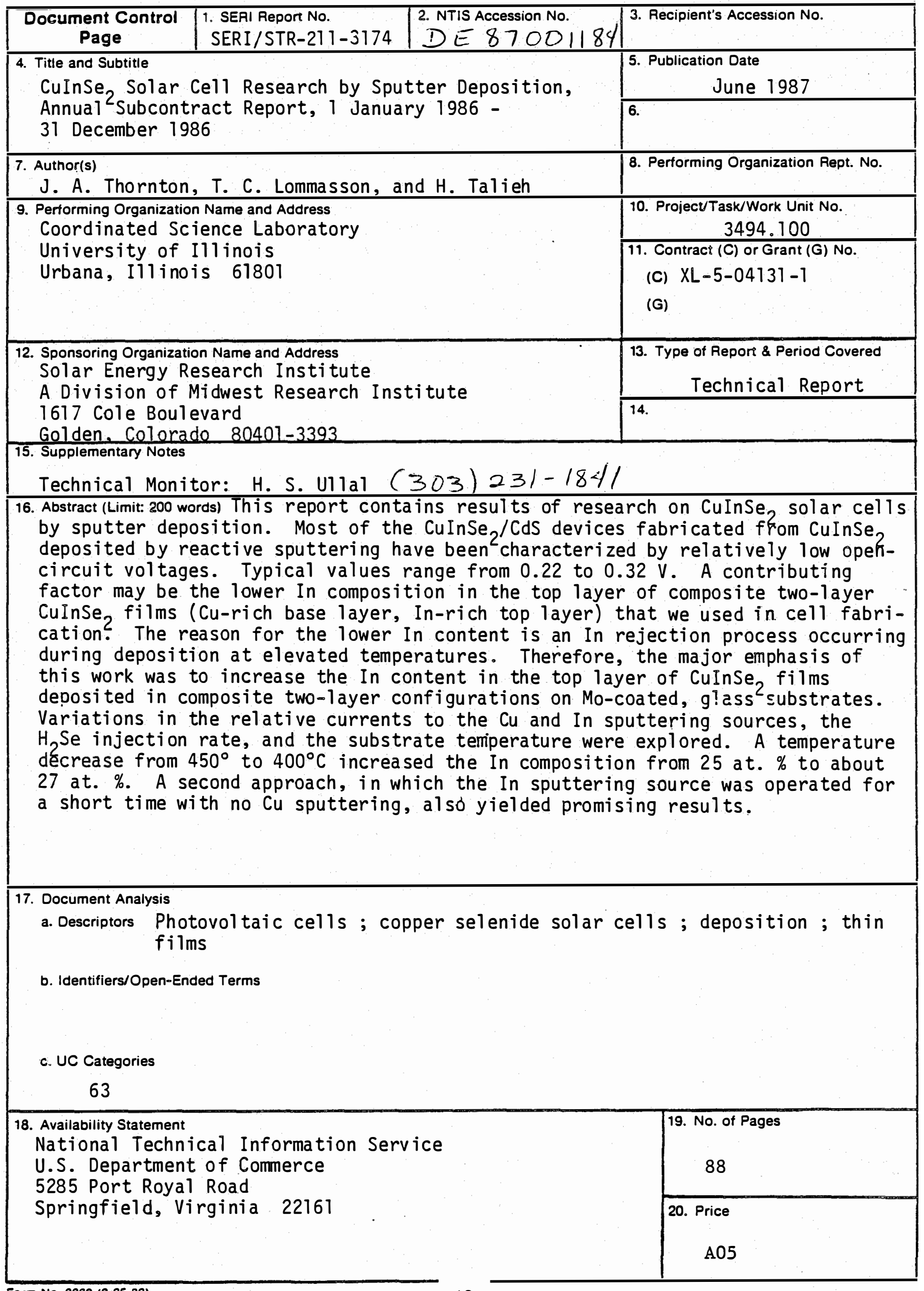




\begin{tabular}{|c|c|}
\hline $\begin{array}{l}\text { 1. SERI Report No. } \\
\text { SERI/STR-211-3190 }\end{array}$ & 3. Recipient's Accession No. \\
\hline \multirow{2}{*}{$\begin{array}{l}\text { 4. Title and Subtitle } \\
\text { Preparation and Properties of Evaporated CdTe Films, } \\
\text { Final Subcontract Report, } 16 \text { February } 1985 \text { - } \\
31 \text { March } 1987\end{array}$} & $\begin{array}{l}\text { 5. Publication Date } \\
\text { July } 1987\end{array}$ \\
\hline & 6. \\
\hline 7. Author(s) & 8. Performing Organization Rept. No. \\
\hline \multirow{2}{*}{$\begin{array}{l}\text { 9. Performing Organization Name and Address } \\
\text { Department of Materials Science and Engineering } \\
\text { Stanford University. } \\
\text { Stanford, California } 94305\end{array}$} & $\begin{array}{l}\text { 10. Project/Task/Work Unit No. } \\
3494.10\end{array}$ \\
\hline & $\begin{array}{l}\text { 11. Contract (C) or Grant (G) No. } \\
\text { (C) XL-4-04022-1 } \\
\text { (G) }\end{array}$ \\
\hline 12. Sponsoring Organization Name and Address & 13. Type of Report \& Period Covered \\
\hline \multirow{2}{*}{$\begin{array}{l}\text { Solar Energy Research Institute } \\
1617 \text { Cole Boulevard } \\
\text { Golden, Colorado } 80401\end{array}$} & Technical Report \\
\hline & 14. \\
\hline
\end{tabular}

15. Supplementary Notes

SERI Technical Monitor: Richard Mitchell

16. Abstract (Limit: 200 words)

Previous work on evaporated CdTe films for photovoltaics showed no clear path to successful p-type doping of CdTe during deposition. Post-deposition annealing of the films in various ambients thus was examined as a means of doping. Anneals were done in Te, Cd, $P$, and As vapors and in vacuum, air, and Ar, all of which showed large effects on series resistance and diode parameters. With As, series resistance values of $\mathrm{In} / \mathrm{p}-\mathrm{CdTe} / \mathrm{graph}$ te structures decreased markedly. This decrease was due to a decrease in grain boundary and/or back contact barrier height, and thus was due to large increases in mobility; the carrier density was not altered substantially. Although the series-resistance decreases were substantial, the diode characteristics became worse. The decreases were not observed when CdS/CdTe cells were fabricated on Te vapor-annealed films. Preparation of $\mathrm{ZnO}$ films by reactive evaporation yielded promising results. Deposition of $p-Z n T e$ films by hot-wall vapor evaporation, using conventional techniques, yielded acceptable films without intentional doping.

17. Document Analysis

a. Descriptors

Photovoltaic cells; thin films; cadmium telluride solar cells; deposition

b. Identifiers/Open-Ended Terms

c. UC Categories

63

18. Availability Statement

National Technical Information Service

U.S. Department of Commerce

5285 Port Royal Road

Springfield, Virginia 22161

19. No. of Pages

52

20. Price

A04 


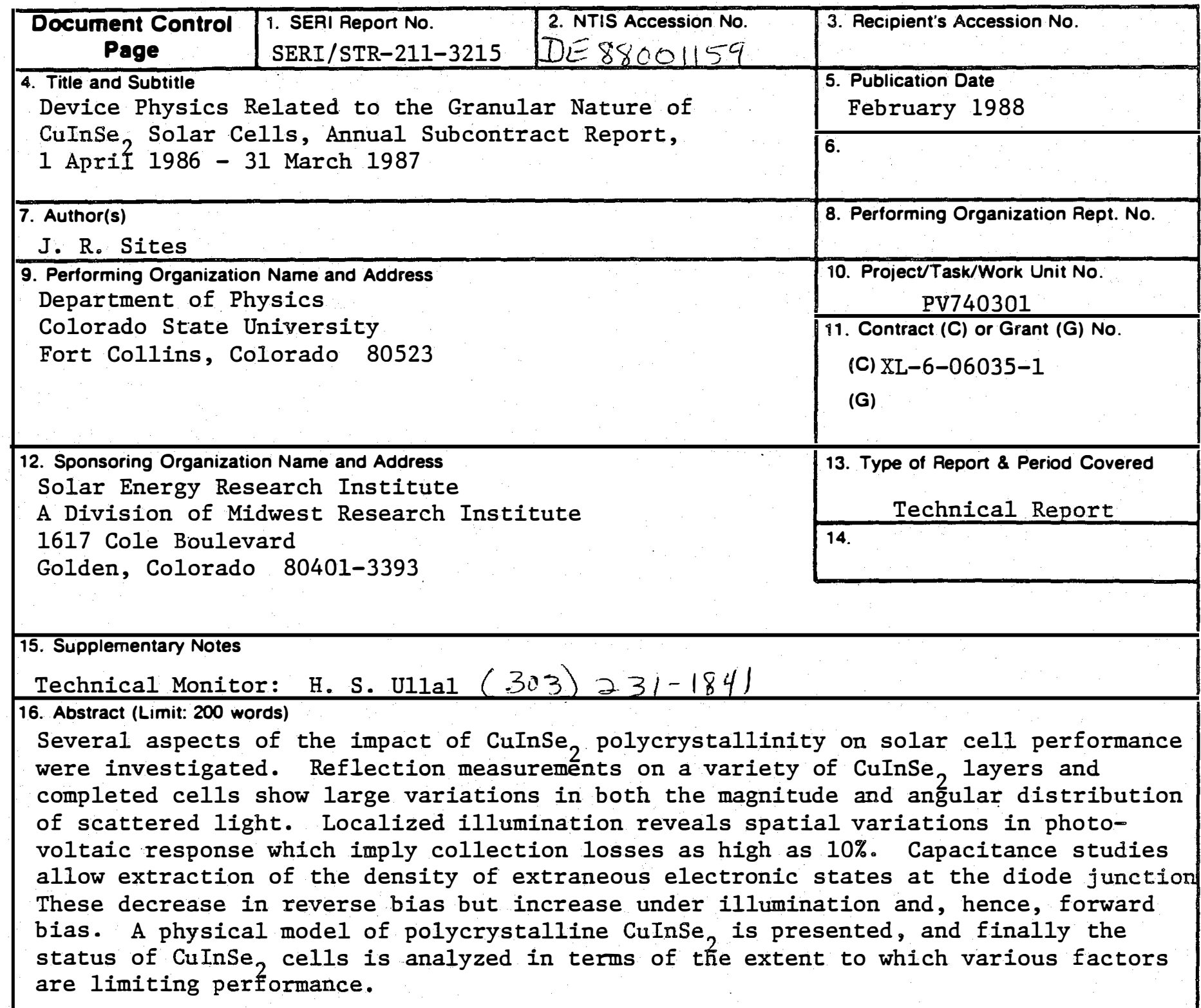

17. Document Analysis

a. Descriptors Photovoltaic cells ; copper indium diselenide solar cells ; efficiency; thin films

b. Identifiers/Open-Ended Terms

c. UC Categories

273

18. Availability Statement

National Technical Information Service

U.S. Department of Commerce

5285 Port Royal Road

Springfield, Virginia 22161

19. No. of Pages

24

20. Price

$\mathrm{A} 02$ 


\begin{tabular}{|c|c|c|}
\hline $\begin{array}{l}\text { Document Control } \\
\text { Page }\end{array}$ & \begin{tabular}{|l|l|} 
1. SERI Report No. & 2. NTIS Accession No. \\
SERI/STR-211-3216 &
\end{tabular} & 3. Recipient's Accession No. \\
\hline \multirow{2}{*}{\multicolumn{2}{|c|}{$\begin{array}{l}\text { 4. Title and Subtitle } \\
\text { Growth and Characterization of Thin Films of } \mathrm{ZnSnP} 2 \text {, } \\
\text { Final Subcontract Report, } 15 \text { October } 1983--31 \text { May } 1987\end{array}$}} & $\begin{array}{l}\text { 5. Publication Date } \\
\text { Feiruary } 1988\end{array}$ \\
\hline & & 6. \\
\hline \multicolumn{2}{|c|}{$\begin{array}{l}\text { 7. Author(s) } \\
\text { P.K. Ajmera and H.Y. Shin }\end{array}$} & 8. Performing Organization Rept. No. \\
\hline \multirow{2}{*}{\multicolumn{2}{|c|}{$\begin{array}{l}\text { 9. Performing Organization Name and Address } \\
\text { Department of Electrical and Computer Engineering } \\
\text { Louisiana State University } \\
\text { Baton Rouge, Louisiana } 70803\end{array}$}} & $\begin{array}{l}\text { 10. Project/Task/Work Unit No. } \\
\text { PV840601 }\end{array}$ \\
\hline & & $\begin{array}{l}\text { 11. Contract (C) or Grant (G) No. } \\
\text { (C) XL-4-03032-2 } \\
\text { (G) }\end{array}$ \\
\hline \multirow{2}{*}{\multicolumn{2}{|c|}{$\begin{array}{l}\text { 12. Sponsoring Organization Name and Address } \\
\text { Solar Energy Research Institute } \\
1617 \text { Cole Boulevard } \\
\text { Golden, Colorado } 80401-3393\end{array}$}} & $\begin{array}{l}\text { 13. Type of Report \& Period Covered } \\
\text { Technical Subcontract } \\
\text { Reoort }\end{array}$ \\
\hline & & 14. \\
\hline \multicolumn{3}{|l|}{ 15. Supplementary Notes } \\
\hline
\end{tabular}

16. Abstract (Limit: 200 words)

This research involved the vacuum deposition of thin films of $\mathrm{ZnSnP}_{2}$. This ternary chalcopyrite semiconductor has a direct energy gap of $1.66 \mathrm{eV}$. Its constituent elements, zinc and phosphorus, are plentiful in the U.S. and tin is readily available from abroad. This makes $\mathrm{ZnSnP}_{2}$ an attractive material for low-cost terrestrial photovoltaic applications. Growth conditions were experimentally determined to obtain near-stoichiometric vacuum growth of thin films of $\mathrm{ZnSnP}_{2}$ on $\mathrm{GaAs}_{\text {, }}$ quartz, and molybdenum substrates utilizing elemental sources. The grown films were characterized.by chemical, electrical, and optical measurements and by morphological studies. Attempts were made to fabricate simple heterostructure devices on the grown layers. This research provides information on the relevant properties of vacuum-grown thin films of $\mathrm{ZnSnP}_{2}$ for its potential application in polycrystalline thin-film PV devices.

17. Document Analysis

a. Descriptors Photovoltaic cells; thin films; semiconductor materials ; deposition

b. Identifiers/Open-Ended Terms

c. UC Categories

273

18. Availability Statement

National Technical Information Service

U.S. Department of Commerce

5285 Port Royal Road

Springfield, Virginia 22161

19. No. of Pages

69

20. Price

A04 


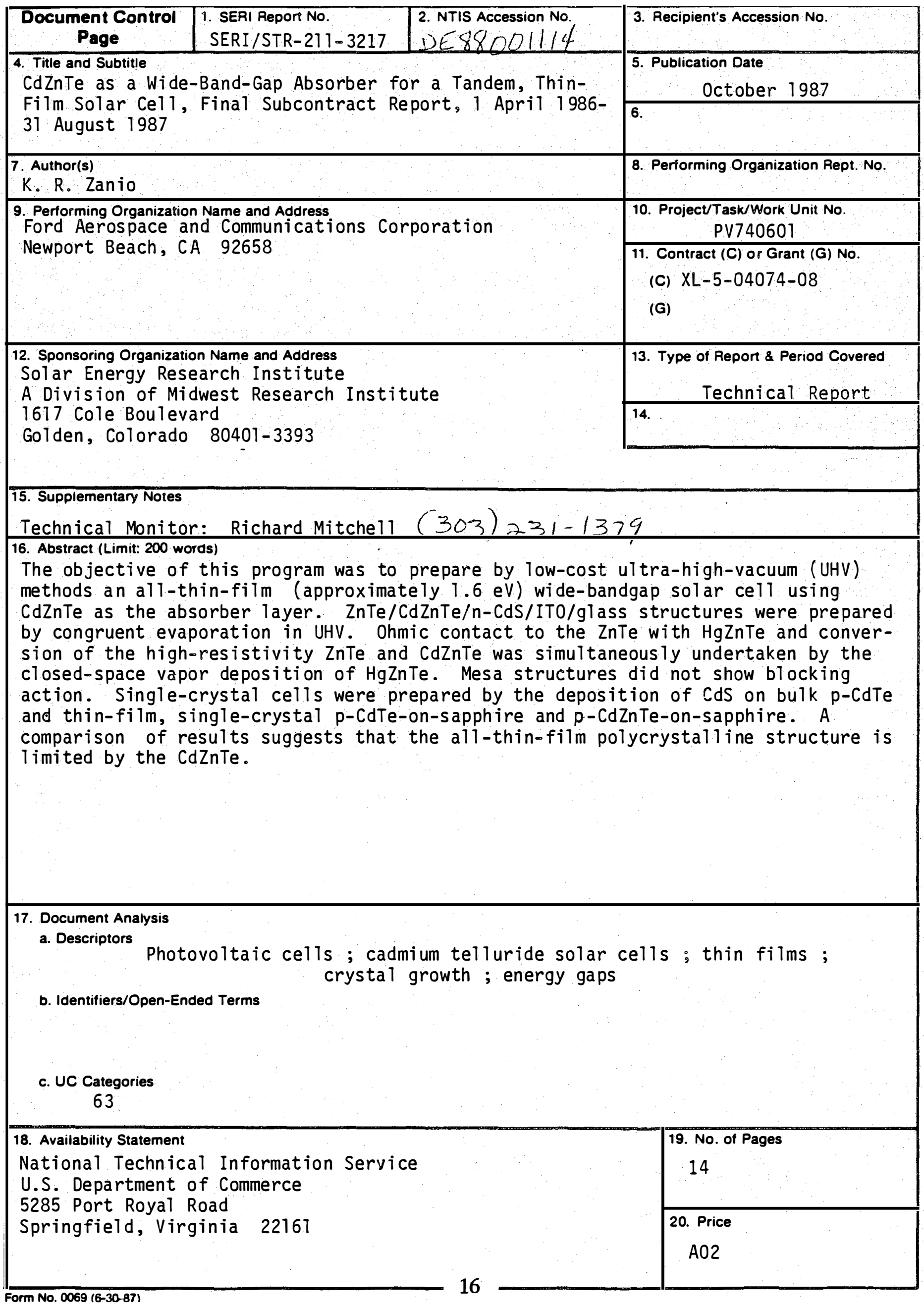




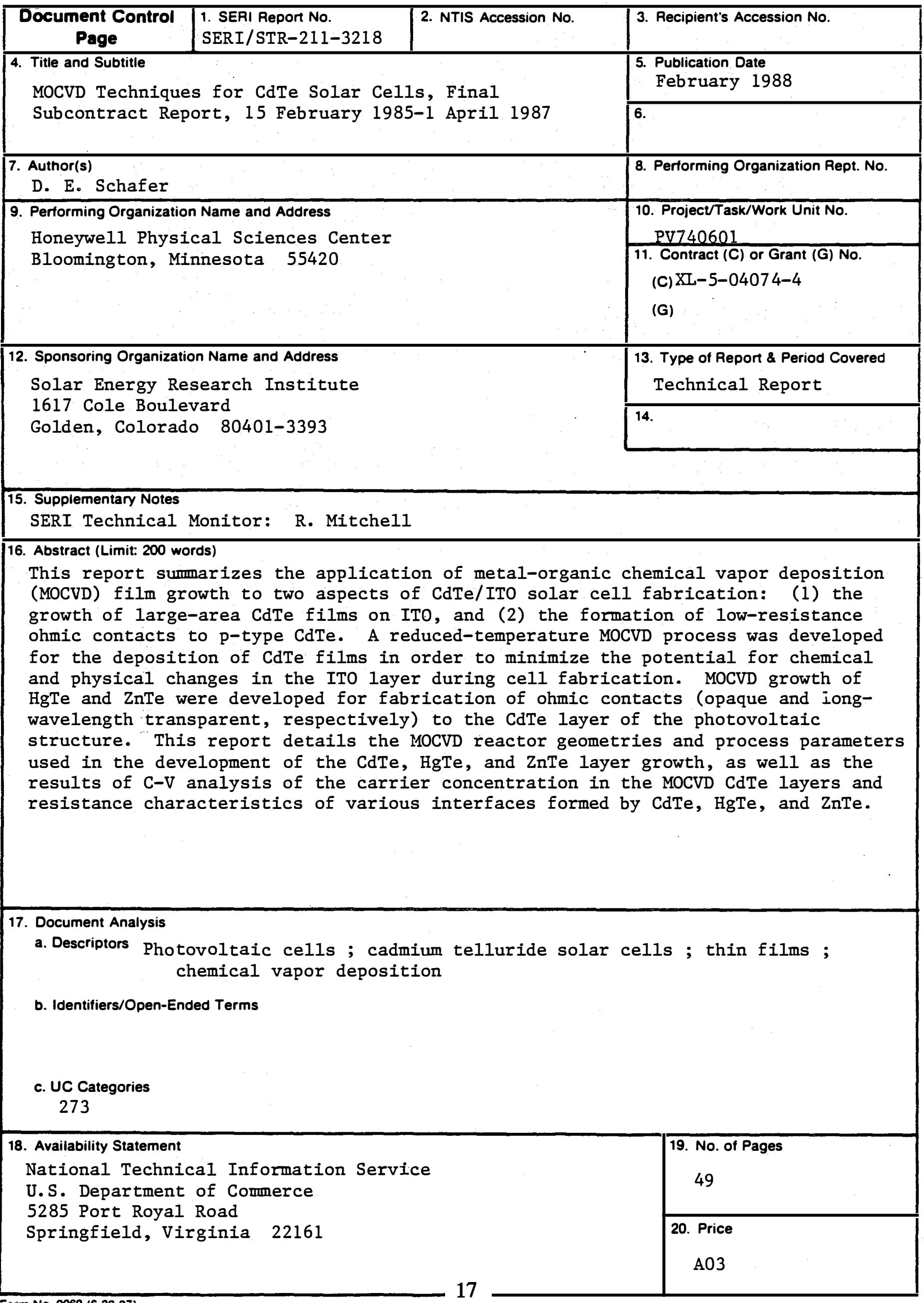




\begin{tabular}{|c|c|c|c|}
\hline $\begin{array}{c}\text { Document Control } \\
\text { Page }\end{array}$ & $\begin{array}{l}\text { 1. SEAI Report No. } \\
\text { SERI / STR-211-3229 }\end{array}$ & $\begin{array}{l}\text { 2. NTIS Accession No. } \\
D E \& 8001183\end{array}$ & 3. Recipient's Accession No. \\
\hline \multirow{2}{*}{\multicolumn{3}{|c|}{$\begin{array}{l}\text { 4. Title and Subtitle } \\
\text { Thin-Film Cadmium Telluride Solar Cells, Annual } \\
\text { Subcontract Report, } 1 \text { May 1986-31 May } 1987\end{array}$}} & $\begin{array}{l}\text { 5. Publication Date } \\
\text { October } 1987\end{array}$ \\
\hline & & & 6. \\
\hline \multicolumn{3}{|l|}{$\begin{array}{l}\text { 7. Author(s) } \\
\text { T. L. Chu }\end{array}$} & 8. Performing Organization Rept. No. \\
\hline \multicolumn{3}{|c|}{$\begin{array}{l}\text { 9. Performing Organization Name and Address } \\
\text { Southern Methodist Univers ity } \\
\text { Dallas, Texas } 75275\end{array}$} & $\begin{array}{l}\text { 10. Project/Task/Work Unit No. } \\
3494.10 \\
\text { 11. Contract (C) or Grant (G) No. } \\
\text { (C) XL-5-05039-1 } \\
\text { (G) }\end{array}$ \\
\hline \multirow{2}{*}{\multicolumn{3}{|c|}{$\begin{array}{l}\text { 12. Sponsoring Organization Name and Address } \\
\text { Solar Energy Research Institute } \\
1617 \text { Cole Boulevard } \\
\text { Golden, Colorado } 80401\end{array}$}} & $\begin{array}{l}\text { 13. Type of Report \& Period Covered } \\
\text { Technica } 1 \text { Report }\end{array}$ \\
\hline & & & 14. \\
\hline \multicolumn{4}{|c|}{$\begin{array}{l}\text { 15. Supplementary Notes } \\
\text { SERI Technical Monitor: H.S. U11al }(303) 231-1841\end{array}$} \\
\hline \multicolumn{4}{|c|}{$\begin{array}{l}\text { 16. Abstract (Limit: } 200 \text { words) } \\
\text { Cadmium telluride, with a room-temperature band-gap energy of } 1.5 \mathrm{eV} \text {, is a } \\
\text { promising thin-film photovoltaic material. The major objective of this research } \\
\text { has been to demonstrate thin-film CdTe heterojunction solar cells with a total } \\
\text { area greater than } 1 \mathrm{~cm} \text { and photovoltaic efficiencies of } 13 \% \text { or more. Thin-film } \\
\text { p-CdTe/CdS/SnO2:F/glass solar cells with an All. } 5 \text { efficiency of } 10.5 \% \text { have been } \\
\text { reported previously. This report contains results of work done on ( } 1 \text { ) the } \\
\text { deposition, resistivity control, and characterization of p-CdTe films by the } \\
\text { close-spaced sublimation process; ( } 2 \text { ) the deposition of large-band-gap window } \\
\text { materials; (3) the electrical properties of CdS/CdTe heterojunctions; ( } 4 \text { ) the } \\
\text { formation of stable, reproducible, ohmic contacts (such as p-HgTe) to p-CdTe; } \\
\text { and (5) the preparation and evaluation of heterojunction solar cells. }\end{array}$} \\
\hline \multicolumn{4}{|l|}{$\begin{array}{l}\text { 17. Document Analysis } \\
\text { a. Descriptors } \\
\text { Pho }\end{array}$} \\
\hline \multicolumn{4}{|c|}{ c. UC Categories } \\
\hline \multicolumn{3}{|c|}{ 18. Availability Statement } & 19. No. of Pages \\
\hline \multirow{2}{*}{\multicolumn{3}{|c|}{$\begin{array}{l}\text { National Technical Information Service } \\
\text { U.S. Department of Commerce } \\
5285 \text { Port Royal Road } \\
\text { Springfield, Virginia } 22161\end{array}$}} & 33 \\
\hline & & & $\begin{array}{l}\text { 20. Price } \\
\text { A03 }\end{array}$ \\
\hline
\end{tabular}




\begin{tabular}{|c|c|c|}
\hline $\begin{array}{l}\text { Document Control } \\
\text { Page }\end{array}$ & \begin{tabular}{|l|l|} 
1. SEAI Report No. & 2. NTIS Accession No. \\
SERI/STR-211-3230 & DE \& $\$ 001122$ \\
\end{tabular} & 3. Recipient's Accession No. \\
\hline \multirow{2}{*}{\multicolumn{2}{|c|}{$\begin{array}{l}\text { 4. Title and Subtitle } \\
\text { Cadmium Sulfide/Copper Ternary Heterojunction Cell } \\
\text { Research, Final Subcontract Report, 1 October 1984- } \\
31 \text { May } 1987\end{array}$}} & $\begin{array}{l}\text { 5. Publication Date } \\
\text { November } 1987\end{array}$ \\
\hline & & 6. \\
\hline \multicolumn{2}{|c|}{$\begin{array}{l}\text { 7. Author(s) } \\
\text { W. E. Devaney. et al. }\end{array}$} & 8. Performing Organization Rept. No. \\
\hline \multirow{2}{*}{\multicolumn{2}{|c|}{$\begin{array}{l}\text { 9. Performing Organization Name and Address } \\
\text { Boeing High Technology Center } \\
\text { Seattle, Washington } 98124-6269\end{array}$}} & 10. Project/Task/Work Unit No. \\
\hline & & PV740301 \\
\hline \multicolumn{2}{|c|}{ Seattle, Washington $98124-6269$} & $\begin{array}{l}\text { 11. Contract (C) or Grant (G) No. } \\
\text { (C) } 2 \mathrm{~L}-4-04068-1 \\
\text { (G) }\end{array}$ \\
\hline \multicolumn{2}{|c|}{ 12. Sponsoring Organization Name and Address } & 13. Type of Report \& Period Covered \\
\hline \multirow{2}{*}{\multicolumn{2}{|c|}{$\begin{array}{l}\text { Solar Energy Research Institute } \\
1617 \text { Cole Boulevard } \\
\text { Golden, Colorado } 80401\end{array}$}} & Technical Report \\
\hline & & 14. \\
\hline
\end{tabular}

SERI Technical Monitor: H. S. Ullal (303) $231-|\varepsilon 4|$

16. Abstract (Limit: 200 words)

This is the Final Technical Report on a 32-month study of $\mathrm{CuInSe}_{2}-$ and $\mathrm{CuInGaSe}_{2}-$ based thin-film polycrystalline heterojunction solar cells. CuInGaSe $\mathrm{films}^{2}$ incorporating $\mathrm{Ga}$ fractions ( $\mathrm{x}$ in $\mathrm{CuIn}_{1-\mathrm{Ga} \mathrm{Se}}$ ) from 0.04 to 1.0 were prepared and characterized. CuInGaSe, /CdZnS heterojunction devices were fabricated for a range of $\mathrm{Ga}$ contents and show the expected variations in $\mathrm{V}$ and spectral response with Ga content. A $10.2 \%$ efficiency (Solar Energy Research Institute (SERI) test, American Society for Testing and Materials (ASTM) 87) was measured for a cell with $\mathrm{Ga}$ fraction of 0.23 , the highest efficiency reported. A CuInSe $/ \mathrm{CdZnS}_{2}$

monolithically interconnected four-cell series string $91 \mathrm{~cm}^{2}$ in area was fabricated with 9.5\% total area efficiency (SERI test, ASTM87). Results are presented on ionassisted deposition of the selenide and sulfide, a new design for the Se evaporation source, indium-tin oxide reactive sputter deposition, and CdZnS films prepared from an E-gun evaporation source. Spectral response and current-voltage characteristic variations with selenide composition before and after heat treatment are discussed. for the CuInSe $/ \mathrm{CdZnS}$ devices. The highest AMl total area efficiency for the $\mathrm{CuInSe}_{2}$ /CdZnS Cell is now $11.9 \%$ (Boeing test, AMl spectrum), with five cells measured over Ehe previously reported high of $10.9 \%$.

17. Document Analysis

a. Descriptors

Photovoltaic cells ; thin films; copper selenide solar cells ; deposition

b. Identifiers/Open-Ended Terms

c. UC Categories

63

18. Availability Statement

National Technical Information Service

U.S. Department of Commerce

5285 Port Royal Road

Springfield, Virginia 22161

19. No. of Pages

130

20. Price

A07 


\begin{tabular}{|c|c|c|c|}
\hline $\begin{array}{l}\text { Document Control } \\
\text { Page }\end{array}$ & $\begin{array}{l}\text { 9. SERI Report No. } \\
\text { SERI/ STR-21 } 7-3249\end{array}$ & $\begin{array}{l}\text { 2. NTIS Accession No } \\
D E \& 80011 \%\end{array}$ & 3. Recipient's Accession No. \\
\hline \multirow{2}{*}{\multicolumn{3}{|c|}{$\begin{array}{l}\text { 4. Title and Subtitle } \\
\text { Stable, High-Efficiency, CuInSe,-Based, Polycrystalline } \\
\text { Thin-Film Tandem Solar Cells, Final Subcontract Report, } \\
16 \text { March } 1984 \text { - } 15 \text { March } 1987\end{array}$}} & $\begin{array}{r}\text { 5. Publication Date } \\
\text { October } 1987\end{array}$ \\
\hline & & & 6. \\
\hline \multicolumn{3}{|c|}{$\begin{array}{l}\text { 7. Author(s) } \\
\text { R. W. Birkmire and J. E. Phillips }\end{array}$} & 8. Performing Organization Rept. No. \\
\hline \multirow{2}{*}{\multicolumn{3}{|c|}{$\begin{array}{l}\text { 9. Performing Organization Name and Address } \\
\text { Institute of Energy Conversion } \\
\text { Univers ity of Delaware } \\
\text { Newark, Delaware }\end{array}$}} & $\begin{array}{l}\text { 10. Project/Task/Work Unit No. } \\
\text { PV740301 }\end{array}$ \\
\hline & & & $\begin{array}{l}\text { 11. Contract (C) or Grant (G) No. } \\
\text { (C) XL-4-04025-1 } \\
\text { (G) }\end{array}$ \\
\hline \multirow{2}{*}{\multicolumn{3}{|c|}{$\begin{array}{l}\text { 12. Sponsoring Organization Name and Address } \\
\text { Solar Energy Research Institute } \\
\text { A Division of Midwest Research Institute } \\
1617 \text { Cole Boulevard } \\
\text { Golden, Colorado } 80401-3393\end{array}$}} & $\begin{array}{l}\text { 13. Type of Report \& Period Covered } \\
\text { Technical Report }\end{array}$ \\
\hline & & & 14. \\
\hline
\end{tabular}

\section{Supplementary Notes}

Technical Monitor: Richard Mitchell (303) 231-1.37\%

16. Abstract (Limit: 200 words) The Tong-term objective of this research was to obtain a stable, thin-film solar cell based on polycrystalline materials with an efficiency of $15 \%$. The approach was to make a tandem cell based on CuInSe $/$ CdS as the bottom cell and CdTe/CdS as the top cel1. An essential feature was to develop a CdTe cell with transparent contacts. A suitable contacting system was developed using transparent conducting oxides (ITO and $\mathrm{SnO}_{2}$ ) in conjunction with a thin layer of copper. Cells were made with efficiencies over $8.5 \%$. A reproducible fabrication process for $\mathrm{CuInSe}_{2} /(\mathrm{CdZn}) \mathrm{S}$ cells was developed based on CuInSe, films grown by vacuum evaporation using Knudsen-type effusion sources. These cells were made with efficiencies over 10\%. The composition of the CuInSe, films can be varied over a considerable range and still yield high-efficiency cells. Adding $Z$ n to the CdS did not increase the $V_{0 c}$ of the devices; analys is showed that the $V$ is not controlled by interface recombination. The effect of oxidizing and reducing heat treatments on CuInSe, cells is to change carrier concentration and thus $V$. Analys is suggests that $J$ is con-

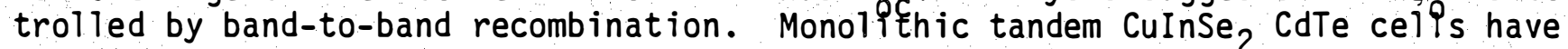
been made with efficiencies of $\sim 3 \%$, demonstrating the feasibility of this approach.

17. Document Analysis

a. Descriptors

Photovoltaic cells ; copper selenide solar cells ; thin films ; efficiency

b. Identifiers/Open-Ended Terms

\section{c. UC Categories}

63

18. Availability Statement

National Technical Information Service

U.S. Department of Commerce

5285 Port Royal Road

Springfield, Virginia 22161

19. No. of Pages

122

20. Price

A06 


\begin{tabular}{|c|c|c|}
\hline $\begin{array}{c}\text { Document Control } \\
\text { Page }\end{array}$ & \begin{tabular}{|l|l|} 
1. SERI Repor No. & 2. NTIS Accession No. \\
SERI/STR-211-3289 & $D E X 80 C 1 / 60)$ \\
\end{tabular} & 3. Recipient's Accession No. \\
\hline \multirow{2}{*}{\multicolumn{2}{|c|}{$\begin{array}{l}\text { 4. Title and Subtitle } \\
\text { Ternary Adamantine Materials for Low-Cost Solar Cells, } \\
\text { Final Subcontract Report, } 1 \text { November } 1984-31 \text { December } \\
1986\end{array}$}} & $\begin{array}{l}\text { 5. Publication Date } \\
\text { February } 1988\end{array}$ \\
\hline & & 6. \\
\hline \multicolumn{2}{|c|}{$\begin{array}{l}\text { 7. Author(s) } \\
\text { D. Cahen and G. Hodes }\end{array}$} & 8. Performing Organization Rept. No. \\
\hline \multicolumn{2}{|c|}{ 9. Performing Organization Name and Address } & 10. ProjectTask/Work Unit No. \\
\hline \multicolumn{2}{|c|}{$\begin{array}{l}\text { Weizmann Institute of Science } \\
\text { Rehovot, Israel }\end{array}$} & $\begin{array}{l}\text { PV7403n1 } \\
\text { (C) IL-5-04132-1 } \\
\text { (G) }\end{array}$ \\
\hline \multicolumn{2}{|c|}{ 12. Sponsoring Organization Name and Address } & 13. Type of Report \& Period Covered \\
\hline \multirow{2}{*}{\multicolumn{2}{|c|}{$\begin{array}{l}\text { Solar Energy Research Institute } \\
1617 \text { Cole Boulevard } \\
\text { Golden, Colorado } 80401-3393\end{array}$}} & Technical Report \\
\hline & & 14. \\
\hline
\end{tabular}

\section{Supplementary Notes}

SERI Technical Monitor: H. S. Ullal ( 303$) 231-1841$ 16. Abstract (Limit; 200 words)

Several methods were investigated to prepare $\operatorname{CuInS}(e)_{2}$, using electroplating techniques near room temperature, to explore them for obtaining photovoltaically active films. No significant photoactivity resulted, unless an annealing step (at greater than or equal to $400^{\circ} \mathrm{C}$ ) was added to the process. Promising PV activity was found only if this anneal was carried out in a $S(e)$-containing atmosphere. Therefore, in part of this project, the two steps, metal deposition and chalcogen incorporation, were separated. These experiments showed that chalcogenization is the most critical step in obtaining films that are PV active. The composition of the films obtained after the chalcogenization step can be varied considerably by a chemical, postannealing treatment. PV activity of films was checked in a simple, rapid way by sputtering $C d$ onto them. Both these junctions, as well as those obtained by ITO deposition, show improved rectification and PV activity, after air anneal of the chalcogenized film, before junction formation. Possible causes for this are discussed. Separate $\mathrm{C}-\mathrm{V}$ experiments on $\mathrm{Al} / \mathrm{CuInSe}{ }_{2} / \mathrm{Mo}$ structures, using CuInSe2/Mo films, provided direct evidence of the persistence of two types of $\mathrm{CuInSe}_{2}$ layers, distinquishable by their doping concentration.

17. Document Analysis
a. Descriptors Photovoltaic cells ; thin films ; copper indium diselenide solar cells ;
chalcogenides ; annealing

\section{b. Identifiers/Open-Ended Terms}

\section{c. UC Categories} 273

18. Availability Statement

National Technical Information Service

U.S. Department of Commerce

5285 Port Royal Road

Springfield, Virginia 22161
19. No. of Pages

44

20. Price

$\mathrm{A03}$ 


\begin{tabular}{|c|c|}
\hline \begin{tabular}{c|l|l|l} 
Document Control & i. SERI Report No. & 2. NTIS Accession No. \\
Page & SERI/STR-211-3365 & DE $8800 / 83$ \\
\end{tabular} & 3. Recipient's Accession No. \\
\hline \multirow{2}{*}{$\begin{array}{l}\text { 4. Title and Subtitle } \\
\text { Thin-Film Cadmium Telluride Solar Cells, Final } \\
\text { Subcontract Report, I May 1985--31 May } 1988\end{array}$} & $\begin{array}{l}\text { 5. Publication Date } \\
\text { June } 1988\end{array}$ \\
\hline & 6. \\
\hline $\begin{array}{l}\text { 7. Author(s) } \\
\text { T. L. Chu }\end{array}$ & 8. Performing Organization Rept. No. \\
\hline 9. Pertorming Organization Name and Address & 10. Projec\&Task/Work Unit No. \\
\hline $\begin{array}{l}\text { Southern Methodist University } \\
\text { Dallas, Texas } 75275\end{array}$ & $\begin{array}{l}\text { 11. Contract (C) or Grant (G) No. } \\
\text { (C) } X L=5-050390-1 \\
\text { (G) }\end{array}$ \\
\hline 82. Sponsoring Organization Name and Address & 13. Type of Report \& Period Covered \\
\hline \multirow{2}{*}{$\begin{array}{l}\text { Solar Energy Research Institute } \\
1617 \text { Cole Boulevard } \\
\text { Goden, Colorado } 80401-3393\end{array}$} & Technical Report \\
\hline & 14. \\
\hline \multicolumn{2}{|l|}{ 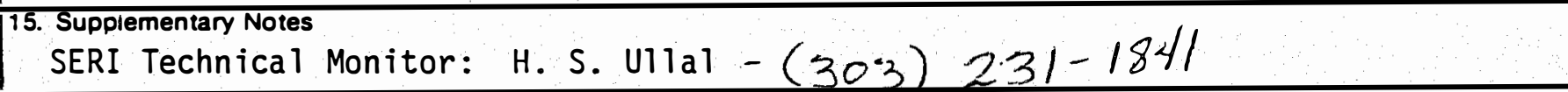 } \\
\hline
\end{tabular}

16. Abstract (Limit: 200 words)

This report describes results of research performed to demonstrate thin-film cadmium telluride heterojunction solar cells with a total area greater than $1 \mathrm{~cm}^{2}$ and efficiencies of $13 \%$ or higher. Efforts were directed to (1) the deposition, resistivity control, and characterization of $p$-CdTe films by combining the vapor of the elements (CVE) and close-spaced sublimation (CSS) techniques; (2) the deposition and characterization of transparent conducting semiconductors: (3) the deposition of p-HgTe as a low-resistance ohmic contact to p-CdTe; (4) the electrical properties of CdS/CdTe heterojunctions; and (5) the preparation and evaluation of heterojunction solar cells. CdS/CdTe solar cells showed the best photovoltaic characteristics, and the best cell had a conversion efficiency of about $10.6 \%$.

17. Document Analysis

a. Descriptors

Photovoltaic cells ; cadmium telluride solar cells; thin films; heterojunctions

b. Identifiers/Open-Ended Terms

c. UC Categories

273

18. Availability Statement

National Technical Information Service

U.S. Department of Commerce

5285 Port Royal Road

Springfield, Virginia 22161

19. No. of Pages

44

20. Price

A03 


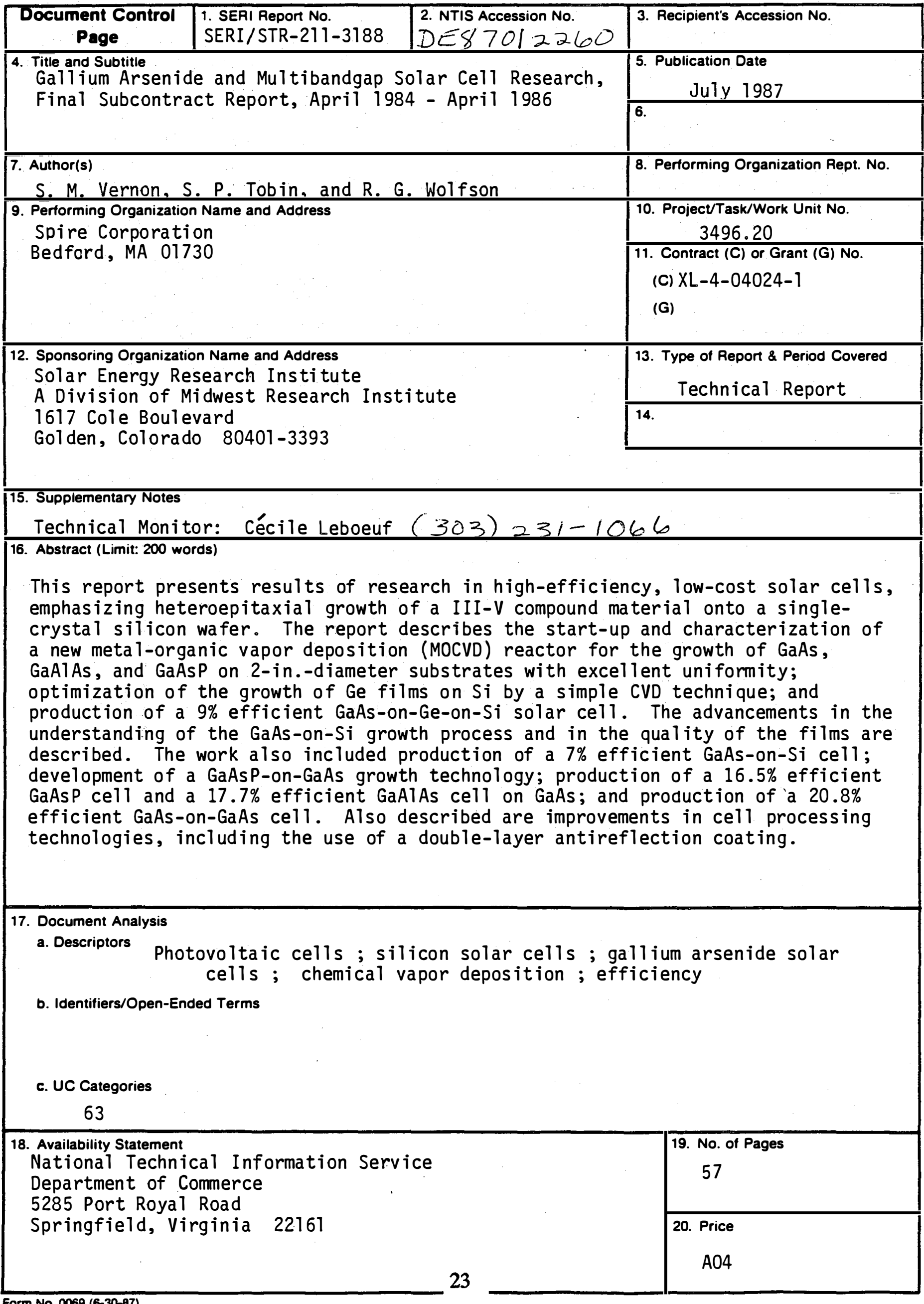




\begin{tabular}{|c|c|}
\hline 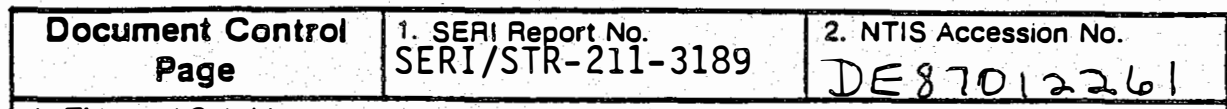 & 3. Recipient's Accession No. \\
\hline \multirow{2}{*}{$\begin{array}{l}\text { 4. Title and Subtitle } \\
\text { Research on Multibandgap Solar Cel1s, Final Subcontract } \\
\text { Report, } 1 \text { March } 1984-31 \text { January } 1987\end{array}$} & $\begin{array}{l}\text { 5. Publication Date } \\
\text { July } 1987\end{array}$ \\
\hline & 6. \\
\hline $\begin{array}{l}\text { 7. Author(s) } \\
\text { J.A. Cape, L.M. Fraas, P.S. McLeod, L.D. Partain }\end{array}$ & 8. Performing Organization Rept. No. \\
\hline \multirow{2}{*}{$\begin{array}{l}\text { 9. Performing Organization Name and Address } \\
\text { Chevron Research Company } \\
\text { Richmond, Cal ifornia } 94802\end{array}$} & 10. Project/Task/Work Unit No. \\
\hline & $\begin{array}{l}3496.20 \\
\text { 11. Contract (C) or Grant (G) No. } \\
\text { (C) } Z L-4-03123-1 \\
\text { (G) }\end{array}$ \\
\hline \multirow{2}{*}{$\begin{array}{l}\text { 12. Sponsoring Organization Name and Address } \\
\text { Solar Energy Research Institute } \\
\text { 1617 Cole Boulevard } \\
\text { Golden, Colorado } 80401\end{array}$} & $\begin{array}{l}\text { 13. Type of Report \& Period Covered } \\
\text { Technical Report }\end{array}$ \\
\hline & 14. \\
\hline \multicolumn{2}{|l|}{$\begin{array}{l}\text { 15. Supplementary Notes } \\
\text { SERI Technical Monitor: Cecile Leboeuf }(303) 231-1066\end{array}$} \\
\hline \multicolumn{2}{|c|}{$\begin{array}{l}\text { 16. Abstract (Limit: } 200 \text { words) } \\
\text { This refort describes research in multibandgap solar cells. In early work, two- } \\
\text { color solar cells with efficiencies exceeding } 20 \% \text { were grown monolithically, } \\
\text { comprising a GaAsP top junction over a GaAs or GaAsSb bottcm junction. Researcher } \\
\text { attempted to understand the effects of lattice mismatch and optimize growth } \\
\text { conditions for these structures. Severe unreproducibility was encountered and } \\
\text { traced to source material impurities. CP } 19 \text {, the p-dopant, was found to be } \\
\text { undependable, and efforts were made to purify it. Impurity effects were also } \\
\text { traced to the arsine (predominantly water vapor) and the gallium alkyls. Efforts } \\
\text { were also made to purify these. Work focused on optimizing component cells of } \\
\text { GaAsP and GaAsSb and on developing the growth process. This, though, did not } \\
\text { lead to higher efficiencies. In developing component cells, work was also done } \\
\text { on optimizing vacuum chemical epitaxy growth conditions (temperatures, flow rates, } \\
\text { III-V ratios, chamber designs, etc.); on developing cell transition layers and } \\
\text { reducing lattice-mismatch effects; on improving cell processing; on reducing } \\
\text { impurities; and on improving material and cell characterization. }\end{array}$} \\
\hline \multirow{2}{*}{\multicolumn{2}{|c|}{$\begin{array}{l}\text { 17. Document Analysis } \\
\text { a. Descriptors } \\
\text { Photovoltaic cells ; gallium arsenide solar cells ; efficiency ; } \\
\quad \text { doped materials; epitaxy } \\
\text { b. Identifiers/Open-Ended Terms }\end{array}$}} \\
\hline & \\
\hline \multicolumn{2}{|l|}{ 18. Availability Statement } \\
\hline \multirow{2}{*}{$\begin{array}{l}\text { National Technical Information Service } \\
\text { U.S. Department of Commerce } \\
5285 \text { Port Royal Road } \\
\text { Springfield, Virginia, } 22161\end{array}$} & \\
\hline & $\begin{array}{l}\text { 20. Price } \\
\text { A05 }\end{array}$ \\
\hline
\end{tabular}




\begin{tabular}{|c|c|c|}
\hline $\begin{array}{l}\text { Document Control } \\
\text { Page }\end{array}$ & \begin{tabular}{|l|l|} 
1. SERI Report No. & 2. NTIS Accession No. \\
SERI/STR-211-3224 & DE 88001115 \\
\end{tabular} & 3. Recipient's Accession No. \\
\hline \multirow{2}{*}{\multicolumn{2}{|c|}{$\begin{array}{l}\text { 4. Title and Subtitle } \\
\text { Research on Single-Crystal CdTe Solar Cells, } \\
\text { Final Subcontract Report, } 1 \text { February 1985- } \\
1 \text { February } 1987\end{array}$}} & $\begin{array}{l}\text { 5. Publication Date } \\
\text { October } 1987\end{array}$ \\
\hline & & 6. \\
\hline \multicolumn{2}{|c|}{$\begin{array}{l}\text { 7. Author(s) } \\
\text { J. M. Borrego, S. K. Ghandhi }\end{array}$} & 8. Performing Organization Rept. No. \\
\hline \multirow{2}{*}{\multicolumn{2}{|c|}{$\begin{array}{l}\text { 9. Performing Organization Name and Address } \\
\text { Electrical, Computer, and Systems Engineering } \\
\text { Department } \\
\text { Rensselaer Polytechnic Institute } \\
\text { Troy, New York } 12180\end{array}$}} & $\begin{array}{l}\text { 10. Project/Task/Work Unit No. } \\
\qquad 3497,10\end{array}$ \\
\hline & & $\begin{array}{l}\text { 11. Contract (C) or Grant (G) No. } \\
\text { (C) ZL-5-04074-2 } \\
\text { (G) }\end{array}$ \\
\hline \multirow{2}{*}{\multicolumn{2}{|c|}{$\begin{array}{l}\text { 12. Sponsoring Organization Name and Address } \\
\text { Solar Energy Research Institute } \\
\text { A Division of Midwest Research Institute } \\
1617 \text { Cole Boulevard } \\
\text { Golden, Colorado } 80401-3393\end{array}$}} & $\begin{array}{l}\text { 13. Type of Report \& Period Covered } \\
\text { Technical Report }\end{array}$ \\
\hline & & 14. \\
\hline
\end{tabular}

15. Supplementary Notes

Technical Monitor: Richard Mitchell (303) 231-1379

16. Abstract (Limit: 200 words) This report outlines two years of work on the growth and characterization of single-crystal CdTe layers, to explore their potential for highefficiency solar cells. It was demonstrated that high-quality layers can be grown by organometallic vapor phase epitaxy (OMVPE), whose photoluminescence peak has a FWHM of $5.8 \mathrm{meV}$, the lowest value for them yet achieved. CdTe layers were extrinsically doped both $n$ - and p-type with indium and arsenic, respectively. The doping level achieved for p-type is the highest yet reported in the literature, achieved for the first time in an OMVPE system. A hole lifetime of $2.0 \mu \mathrm{m}$ was measured. In the n-type material, five deep levels were isolated; their capture cross section, energy level, and concentration were determined. A thermodynamic analysis was made to identify their defect character. Both Schottky and $p-n$ junction devices were produced on these layers. The diode characteristics were superior to those of GaAs so this is a potentially superior material for solar cells.

17. Document Analysis

a. Descriptors Photovoltaic cells ; cadmium telluride solar cells; semiconductor materials ; Schottky barrier solar cells

b. Identifiers/Open-Ended Terms

c. UC Categories

63

18. Availability Statement

National Technical Information Service

U.S. Department of Commerce

5285 Port Royal Road

Springfield, Virginia 22161

19. No. of Pages

100

20. Price

A05 


\section{ADDITIONAL PUBLICATIONS AND SOURCES}

The following publications were produced under the DOE Photovoltaics Program or are widely available publications in which substantial DOE-supported work is reported. Those that and are available from the National Technical Information Service (NTIS) can be purchased with the NTIS order form provided hereafter.

Annual Report, Photovoltaic Measurements and Performance Branch, FY 1988. (January 1989). SERI/PR-213-3590. 160 pp. Available NTIS: Order No. DE89009500.

Annual Report, Photovoltaic Program Branch, FY 1988. (March 1989). SERI/PR-2113483. 302 pp. Available NTIS: Order No. DE89000898.

Annual Report, Solid State Photovoltaic Research Branch, FY 1988. (July 1989). SERI/PR-212-3494. 265 pp. Available NTIS: Order No. DE89009463.

Conference Record of the Nineteenth IEEE Photovoltaic Specialists Conference - 1987; New Orleans, Louisiana; May 4-8, 1987. (1987). New York: The Institute of Electrical and Electronics Engineers, Inc.; 1530 pp. Available from IEEE, 345 E. 47th St., New York, NY 10017.

Conference Record of the Twentieth IEEE Photovoltaic Specialists Conference - 1988; Las Vegas, Nevada; September 26-30, 1988. (1988). New York: The Institute of Electrical and Electronics Engineers, Inc.; 2 Volumes, 1664 pp. Available from IEEE, 345 E. 47th St., New York, NY 10017.

Current Abstracts: Photovoltaic Energy, Electricity from Sunlight. Prepared by the Office of Scientific and Technical Information for the Office of Conservation and Renewable Energy, U. S. Department of Energy. Nov.-Dec. 1989, PB89-933006. Available from the Office of Scientific and Technical Information, P.O. Box 62, Oak Ridge, TN 37831.

Current Abstracts: Photovoltaic Energy, Electricity from Sunlight. Prepared by the Office of Scientific and Technical Information for the Office of Conservation and Renewable Energy, U. S. Department of Energy. Jan.-Feb. 1990, PB90-933001. Available from the Office of Scientific and Technical Information, P.O. Box 62, Oak Ridge, TN 37831.

Photovoltaic Energy Program Summary, Volume I: Overview, Fiscal Year 1988. (January 1989). DOE/CH10093-40. Golden, CO: Solar Energy Research Institute; 15 pp. Prepared for the U.S. Department of Energy, Assistant Secretary, Conservation and Renewable Energy, Washington, DC, by the Solar Energy Research Institute, Golden, Colorado. Available NTIS: Order No. DE89000855.

Photovoltaic Energy Program Summary, Volume II; Research Summaries Fiscal Year 1988. (January 1989). DOE/CH10093-39. Golden, CO: Solar Energy Research Institute; 188 pp. Prepared for the U.S. Department of Energy, Assistant Secretary, Conservation and 
Renewable Energy, Washington, DC, by the Solar Energy Research Institute, Golden, Colorado. Available NTIS: Order No. DE89000832.

Photovoltaics: Entering the 1990s. (November 1989). SERI/SP-220-3461. 42 pp. Produced by the Development and Communications Office. Available NTIS: Order No. DE89009509.

Photovoltaics Technical Information Guide: Second Edition. (August 1988). SERI/SP320-3328. 118 pp. Available NTIS: Order No. DE88001184.

Riordan, C. J.; Hulstrom, R. L.; Cannon, T. W.; Stoffel, T. L.; Myers, D. R.; (February 1989). Photovoltaic Advanced Research and Development Project, Solar Radiation Research, Annual Report, 1 October 1987 - 30 September 1988. SERI/PR-215-3445. 24 pp. Available NTIS: Order No. DE89000884.

Ullal, H. S.; Zweibel, K. (December 1989). Progress in Thin Film Solar Photovoltaic Technologies. SERI/TP-211-3604. $12 \mathrm{pp}$. Prepared for the 9th Miami International Congress on Energy and Environment, Miami Beach, Florida, 11-13 December 1989. Available NTIS: Order No. DE89009513.

Ullal, H. S.; Zweibel, K.; Mitchell, R. L. (November 1989). U.S. Polycrystalline Thin Film Solar Cell Program. SERI/TP-211-3595. 6 pp. Prepared for the Materials Research Society 1989 Fall Meeting, 27 November - 2 December 1989, Boston, Massachusetts. Available NTIS: Order No. DE89009506.

Ullal, H. S.; Zweibel, K.; Sabisky, E. S.; Surek, T. (August 1988). Solar Photovoltaic Technology: The Thin Film Option. SERI/TP-211-3390. $10 \mathrm{pp}$. Presented at the AIChE Summer National Meeting, Denver, Colorado, 21-24 August 1988. Available NTIS: Order No. DE88001195.

U.S. Photovoltaic Patents: 1951-1987. (September 1988). SERI/SP-210-3357. 616 pp. Available NTIS: Order No. DE88001178.

Zweibel, K. (May 1989). Thin Film Photovoltaics. SERI/TP-211-3501. 7 pp. Prepared for the 24th Intersociety Energy Conversion Engineering Conference, Washington, D.C., 6-11 August 1989. Available NTIS: Order No. DE89009425. 
For DTIC Users Only

Date

PURCHASER:

DTIC User Code

Contract Number

(last 6 characters only)
EXPRESS/RUSH

REGULAR SERVICE

TELECOPIER

TELEX
(800) $336-4700$

(703) $487-4700$

(703) $487-4650$

(703) $321-8547$

89-9405
BILLING OFFICE TELEPHONE: 11

ATTENTION

$\overline{\text { (Last Name) }} \overline{(\text { Intial) }}$

(Company. University. Agency)

(BIdg. Suite. Dept.)

(Street. PO Box)

U.S.

$$
\text { (City) }
$$

(State)

$(Z \mid p)$

Foreign

(City. State or Province. Country)
SHIP TO: (Enter ONLY if different from address at left)

ATTENTION:

$\overline{\text { (Last Name) }} \overline{\text { (Initial) }}$

(Company. University. Agency)
(Street. P.O. Box)

U.S.

(City)

(State)

$(Z, p)$

Foreign:

(City. State or Province. Country)

ORDERING OPTIONS: All Regular demand orders are shipped First Class Mail or equivalent service to all U.S. addresses. (For First Class Mail or equivalent service to Canadian and Mexican addresses add $\$ 3$ per item; for all other addresses add \$6 per item.) You may also elect Express or Rush Service. For a $\$ 20$ per item charge your Express order will be processed within 24 hours and delivered by overnight courier. For a $\$ 10$ peritem charge your Rush order will be processed within 24 hours and mailed First Class Mail (or equivalent) or you may pick up your Rush order at NTIS within 24 hours for a $\$ 7.50$ per item charge. -A Shipping and Handling fee must be applied to all Regular orders, but does not apply to Express, Rush or subscription orders.

USE THIS SECTION ONLY IF YOU KNOW THE DOCUMENT NUMBER. IF YOU ARE ORDERING BY TITLE, TURN THE PAGE.

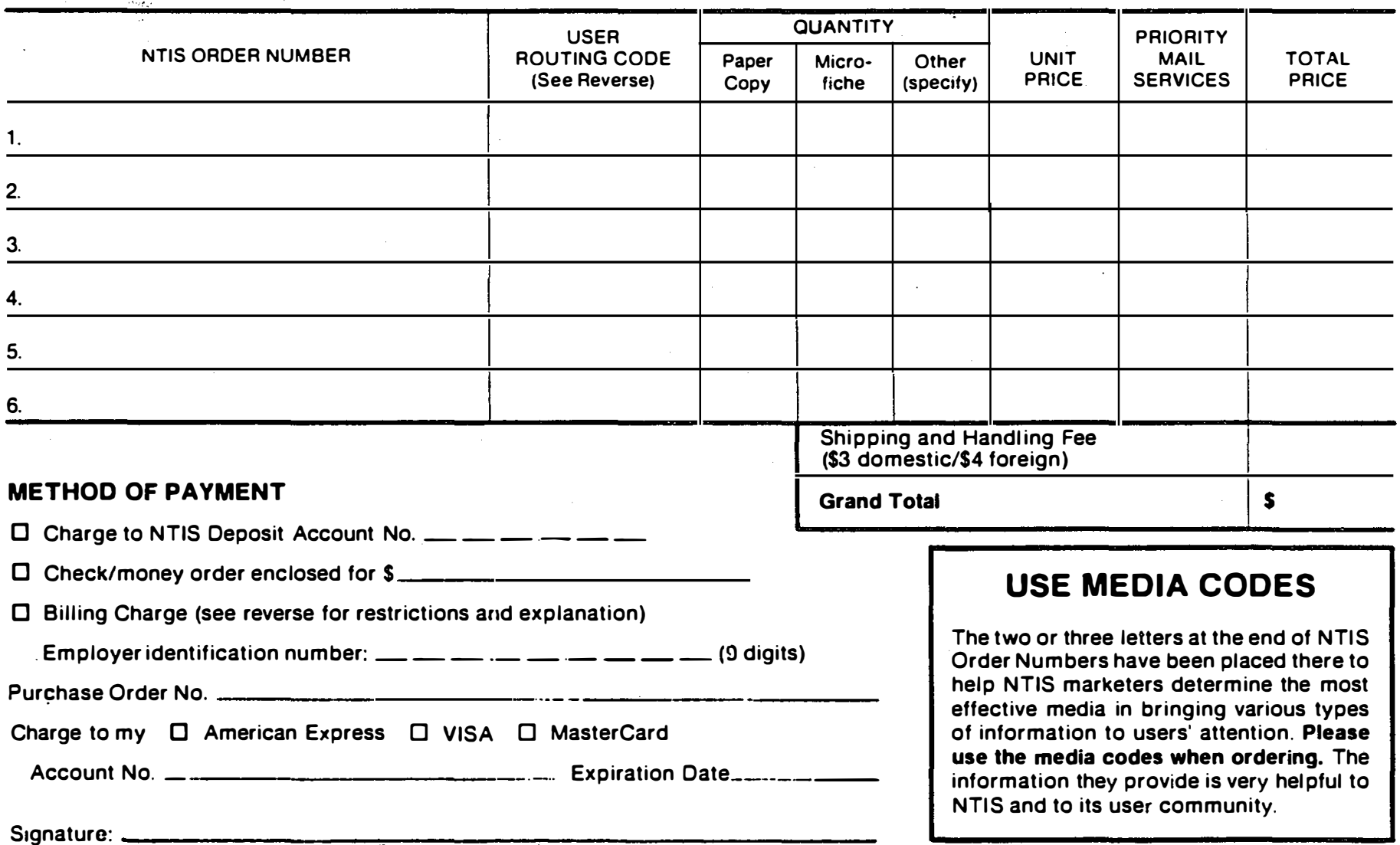


USER ROUTING CODE: NTIS can label each item for routing within your organization. If you want this service put your routing code in the box marked USER ROUTING CODE (Limit eight characters).

BILLING SERVICE: This service is restricted to North American business locations for an extra $\$ 7.50$ per order (orper Custom Search). The business employer identification number plus the phone number of the office paying the bill are required to process these requests. A late payment charge will be applied to all billings more than 30 days overdue.

FOR TELEPHONE ORDERS, CALL THE NTIS SALES DESK - 703/487-4650

\section{ORDERING MAGNETIC TAPE: (check mode)}
$\square$ Track
$\square 800 \mathrm{bpi}$
$\square$ \$600 bpi
$\square 6250 \mathrm{bpi}$
(odd parity)

ORDERING BY TITLE: Use this section if you do not know the document number, but you do know the title. Please give us as much information as you can to help us to fill your order correctly.

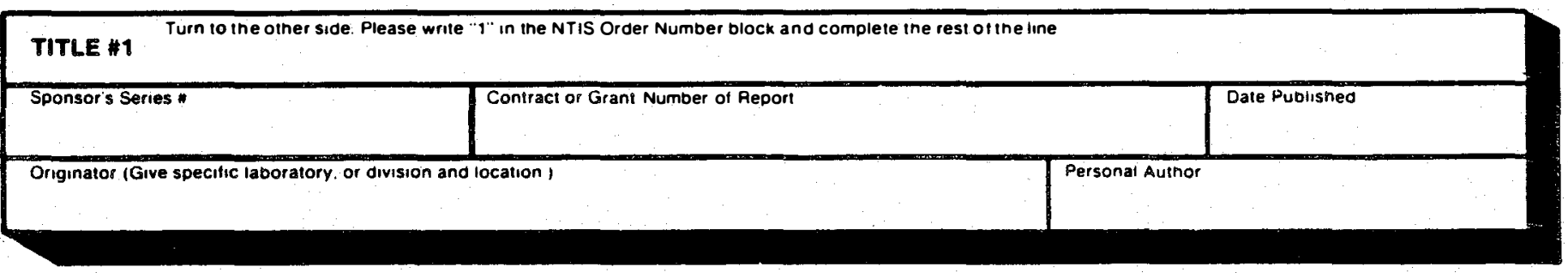

TITLE \#2 Turn tu the other side Please write $2 "$ in the NTIS Order Number block and complete the rest of the line

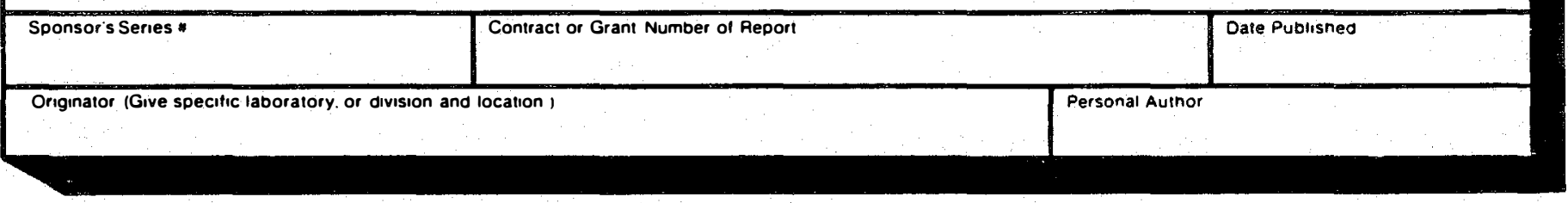

TITLE \#3

\begin{tabular}{|l|l|l|l|l|}
\hline Sponsor's Series \# & Contract or Grant Number of Report & Dublished \\
\hline Originator IGive specific taboratory, or division and locatıon) & Personal Author \\
\hline
\end{tabular}

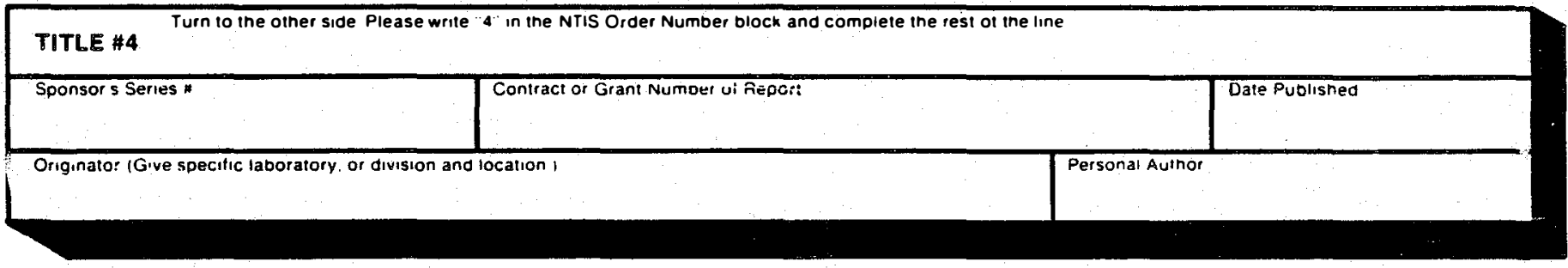

TITLE \#5

Turn to the other side Please write 5 in the NTIS Order Number block and cumplete the rest of the line 
Contacts: SERI Photovoltaic Program Branch Personnel

\begin{tabular}{lll}
\hline Task Area & Contact Name & Telephone* \\
\hline PV Program Branch & Thomas Surek, Manager & $231-1371$ \\
& Kathy Summers, Admin. Assist. & $231-1395$ \\
& Thomas S. Basso & $231-7035$ \\
Amorphous Silicon & William Wallace & $(202) 586-7307$ \\
Research Project & Werner Luft, Acting Manager & $231-1823$ \\
& Byron Stafford & $231-7126$ \\
High-Efficiency Concepts, & John Benner, Manager & $231-1396$ \\
Crystalline Silicon Materials, & Cecile Leboeuf & $231-1066$ \\
and University Program & Bushan Sopori & $231-1383$ \\
Polycrystalline & Kenneth Zweibel, Manager & $231-7141$ \\
Thin Films & Richard Mitchell & $231-1379$ \\
& Harin Ullal & $231-1841$ \\
New Ideas Program & Richard Mitchell, Manager & $231-1379$ \\
\hline
\end{tabular}

*Area code (303); FTS number 327-XXXX.

We are in the process of updating the mailing list for photovoltaic documents. If you would like to remain on the distribution list for this and other documents, please fill in the information below, detach the order form, and mail it to:

Photovoltaic Program Branch

Solar Energy Research Institute

1617 Cole Blvd.

Golden, CO 80401-3393

Name:

Company:

Mailing Address:

City, State:

Zip Code: 